University of Wollongong

Research Online

Faculty of Engineering and Information

Faculty of Engineering and Information

Sciences - Papers: Part B

Sciences

2020

Experimental investigation and performance evaluation of a mixed-flow air to air membrane enthalpy exchanger with different configurations

Ahmed Khafeef Obaid Al-Bdoor

University of Wollongong, akoab305@uowmail.edu.au

Zhenjun $\mathrm{Ma}$

University of Wollongong, zhenjun@uow.edu.au

Paul Cooper

University of Wollongong, pcooper@uow.edu.au

Follow this and additional works at: https://ro.uow.edu.au/eispapers1

Part of the Engineering Commons, and the Science and Technology Studies Commons

Research Online is the open access institutional repository for the University of Wollongong. For further information contact the UOW Library: research-pubs@uow.edu.au 


\title{
Experimental investigation and performance evaluation of a mixed-flow air to air membrane enthalpy exchanger with different configurations
}

\author{
Abstract \\ (C) 2019 Elsevier Ltd This paper presents an experimental investigation and performance evaluation of a \\ mixed-flow air to air membrane enthalpy exchanger with different flow configurations. The moisture \\ diffusivity, water contact angle and elastic modulus of five porous membranes were first experimentally \\ determined using a wet cup test method, a contact angle meter and the tensile test, respectively. The five \\ porous membranes investigated consisted of two Polyvinylidene difluoride membranes with the mean \\ pore diameters of $0.22 \mu \mathrm{m}$ (PVDF22) and $0.45 \mu \mathrm{m}$ (PVDF45) respectively, two Nylon membranes with 0.1 \\ $\mu \mathrm{m}$ and $0.45 \mu \mathrm{m}$ pore sizes respectively and one Polyethersulfone (PES) membrane with a $0.1 \mu \mathrm{m}$ pore \\ size. The optimal membrane was then identified and used to fabricate an enthalpy exchanger. Lastly, the \\ performance of the enthalpy exchanger with different mixed-flow configurations was experimentally \\ investigated. The results showed that the PVDF45 membrane offered the highest moisture diffusivity \\ $(1.91 \times 10-6 \pm 2.42 \times 10-8 \mathrm{~m} 2 / \mathrm{s})$ with hydrophilic surface and a relatively high elastic modulus $(4.97 \times$ \\ $108 \pm 3.86 \times 107 \mathrm{~Pa}$ ). It was shown that the enthalpy exchanger with Z-shape flow of the supply air \\ stream and $И$-shape flow of the exhaust air stream at an entrance ratio of 0.25 offered the best thermal \\ performance as the sensible, latent and total effectiveness increased by $12.3 \%, 15.1 \%$ and $14.6 \%$ \\ respectively, when the flow rate was $0.3 \mathrm{l} / \mathrm{s}$, as compared to that of the pure cross flow. The same flow \\ configuration was able to recover the highest energy among all configurations investigated. \\ Disciplines \\ Engineering | Science and Technology Studies

\section{Publication Details} \\ Al-Bdoor, A., Ma, Z. \& Cooper, P. (2020). Experimental investigation and performance evaluation of a \\ mixed-flow air to air membrane enthalpy exchanger with different configurations. Applied Thermal \\ Engineering, 166 114682-1-114682.
}




\title{
Experimental investigation and performance evaluation of a
}

\section{mixed-flow air to air membrane enthalpy exchanger with} different configurations

\author{
Ahmed K. Albdoor ${ }^{\mathrm{a}, \mathrm{b}}$, Zhenjun Ma ${ }^{\mathrm{a},{ }^{*}}$, Paul Cooper ${ }^{\mathrm{a}}$ \\ ${ }^{a}$ Sustainable Buildings Research Centre, University of Wollongong, 2522, Australia \\ ${ }^{b}$ Department of Mechanical Techniques, Al-Nasiriyah Technical Institute, Southern \\ Technical University, 64001, Thi-Qar, Iraq \\ *Email: zhenjun@uow.edu.au
}

Abstract: This paper presents an experimental investigation and performance evaluation of a mixed-flow air to air membrane enthalpy exchanger with different flow configurations. The moisture diffusivity, water contact angle and elastic modulus of five porous membranes were first experimentally determined using a wet cup test method, a contact angle meter and the tensile test, respectively. The five porous membranes investigated consisted of two Polyvinylidene difluoride membranes with the mean pore diameters of $0.22 \mu \mathrm{m}$ (PVDF22) and $0.45 \mu \mathrm{m}$ (PVDF45) respectively, two Nylon membranes with $0.1 \mu \mathrm{m}$ and $0.45 \mu \mathrm{m}$ pore sizes respectively and one Polyethersulfone (PES) membrane with a $0.1 \mu \mathrm{m}$ pore size. The optimal membrane was then identified and used to fabricate an enthalpy exchanger. Lastly, the performance of the enthalpy exchanger with different mixed-flow configurations was experimentally investigated. The results showed that the PVDF45 membrane offered the highest moisture diffusivity $\left(1.91 \times 10^{-6} \pm 2.42 \times 10^{-8} \mathrm{~m}^{2} / \mathrm{s}\right)$ with hydrophilic surface and a relatively high elastic modulus $\left(4.97 \times 10^{8} \pm 3.86 \times 10^{7} \mathrm{MPa}\right)$. It was shown that the enthalpy exchanger with Z-shape flow of the supply air stream and И-shape flow of the exhaust air stream at an entrance ratio of 0.25 offered the best thermal performance as the sensible, latent and total effectiveness increased by $12.3 \%, 15.1 \%$ and $14.6 \%$ respectively, when the flow rate 
was $0.3 \mathrm{l} / \mathrm{s}$, as compared to that of the pure cross flow. The same flow configuration was able to recover the highest energy among all configurations investigated.

27 Keywords: Enthalpy exchanger; moisture diffusivity; mixed-flow configuration;

28 experiments; performance evaluation

29 Nomenclature

$J \quad$ mass flux $\left(\mathrm{kg} / \mathrm{m}^{2} . \mathrm{s}\right)$

$G \quad$ weight change (kg)

$t \quad$ time during which weight change occurred (s)

$A_{c} \quad$ test cup area $\left(\mathrm{m}^{2}\right)$

$w \quad$ absolute humidity $(\mathrm{kg} / \mathrm{kg})$

$D_{m} \quad$ moisture diffusivity $\left(\mathrm{m}^{2} / \mathrm{s}\right)$

$R_{m} \quad$ moisture diffusion resistance $\left(\mathrm{m}^{2} . \mathrm{s} / \mathrm{kg}\right)$

$m \quad$ mass flow rate $(\mathrm{kg} / \mathrm{s})$

$P c \quad$ power consumption (W)

$T \quad$ temperature $\left({ }^{\circ} \mathrm{C}\right)$

$h \quad$ specific enthalpy $(\mathrm{J} / \mathrm{kg})$

$h_{\text {heat }}$ convective heat transfer coefficient $\left(\mathrm{kW} / \mathrm{m}^{2} . \mathrm{K}\right)$

$Q \quad$ volume flow rate $\left(\mathrm{m}^{3} / \mathrm{s}\right)$

cp specific heat $(\mathrm{kJ} / \mathrm{kg} . \mathrm{K})$

$A_{t} \quad$ membrane area $\left(\mathrm{m}^{2}\right)$

$D_{h} \quad$ hydraulic diameter (m)

$A_{c s} \quad$ channel cross section area $\left(\mathrm{m}^{2}\right)$

$P_{d} \quad$ channel perimeter (m)

$\mathrm{Nu} \quad$ Nusselt number

$h_{\text {mass }}$ convective mass transfer coefficient $(\mathrm{m} / \mathrm{s})$ 
Sh Sherwood number

$D_{a} \quad$ moisture diffusivity of air $\left(\mathrm{m}^{2} / \mathrm{s}\right)$

$\Delta p \quad$ pressure drop (pa)

\section{Greek letters}

$\varepsilon \quad$ effectiveness

$\rho_{a} \quad$ air density $\left(\mathrm{kg} / \mathrm{m}^{3}\right)$

$\lambda \quad$ air thermal conductivity ( $\mathrm{kW} / \mathrm{m} . \mathrm{K}$ )

\section{Subscripts}

in inside the cup

out outside the cup

$\min$ minimum

$m \quad$ mean

lm logarithmic

$s \quad$ supply/sensible

e exhaust

$i \quad$ inlet

$o \quad$ outlet

$l \quad$ latent

$t \quad$ total

31

$32 \quad$ Abbreviations

MDR moisture diffusion resistance $\left(\mathrm{m}^{2} . \mathrm{s} / \mathrm{kg}\right)$

TER total energy recovered (W)

$R H \quad$ relative humidity $(\%)$ 
The undesirable increase in energy demand of the building sector could result from the unsustainable design and intensive usage of Heating, Ventilation and Air Conditioning (HVAC) systems [1]. The primary energy demand in the building sector is around $40 \%$ of the total world energy, among which about $50 \%$ was consumed by HVAC systems $[2,3]$. Therefore, improving energy efficiency of HVAC systems is becoming a priority for building designers and practitioners to promote building energy efficiency and sustainability [4-6].

Air-to-air energy recovery ventilators (ERVs) are among the environmentally friendly devices that can be used to save energy in buildings and reduce greenhouse gas emissions [7]. ERVs can recover sensible and latent energy in the exhausted air stream to pre-condition the incoming outdoor air stream [8], providing opportunities for energy savings. Membrane enthalpy exchanger (MEE) is one type of ERVs using semi-permeable membranes to separate the air streams to exchange heat and moisture simultaneously from one air stream to the other air stream $[9,10]$. MEEs have been widely used in building applications as they can offer less embodied energy, simplicity, low contamination crossover and high performance [11].

The membrane properties and the air flow configurations inside the enthalpy exchanger are among the critical parameters that affect the performance of the MEE [12]. Membrane properties such as moisture diffusivity and module of elasticity are important for membrane selection [13]. Both latent effectiveness and total effectiveness are influenced by the moisture diffusivity of the membrane used to fabricate MEEs $[14,15]$. On the other hand, the pressure difference across the semi-permeable membrane may cause membrane deflection, which will affect the flow distribution and decrease the exchanger performance. The study from Larson et al. [16] showed that significant membrane deflection can occur by applying a moderate pressure difference on both sides of the membrane. It was shown that membrane deflection was inversely proportional to the modulus of elasticity. The deflection increased with the decrease of the modulus of elasticity, resulting in a decrease in the performance of the MEE. In general, 
the maldistribution due to membrane deflection can be mitigated by using membranes with high modulus of elasticity [17].

Another design parameter that can influence the performance of the MEE is the flow configuration. It is well known that the best performance can be generally achieved by using the counter flow configuration [18-21]. However, it is usually difficult to achieve such configuration in practice due to the fact that the inlet and outlet ducts will be overlapped with each other at the same side, and sealing will be problematic [19-21]. Therefore, a new flow configuration named mixed-flow configuration (i.e. hybrid flow) has been developed to reduce the manufacturing challenges of the counter flow configuration and to maintain the high effectiveness of the MEE.

The mixed-flow configuration could consist of two or more basic flow configurations (i.e. parallel, cross and counter). Various flow combinations can be used to obtain the hybrid flow. For instance, Nassif et al. [22-24] experimentally and numerically investigated the performance of a MEE with a Z-shape flow configuration. It was found that the annual energy consumption of an air conditioning system integrated with this Z-shape MEE was decreased by $8 \%$ as compared to a conventional HVAC system. Zhang [25] developed a quasi-counter flow membrane-based total heat exchanger. The results showed that the effectiveness of this quasi-counter flow configuration was between the cross-flow configuration and counter-flow configuration. It was further revealed that the flow would be divided into three zones, including two cross flow zones near the inlets and the outlets respectively, and a counter flow zone at the middle part. Al-Waked et al. [26] numerically investigated the thermal performance of a MEE with various flow configurations including Z-shape, L-shape and quasi-counter flow under turbulent flow conditions. It was found that the quasi-counter flow could be the best option among different flow configurations investigated. 
Based on the above review, it can be seen that there are a few hybrid flow configurations for air to air MEEs that have been proposed. However, a detailed experimental investigation and performance comparison among different flow configurations has not been thoroughly conducted. This paper presents an experimental investigation of the performance of a mixedflow air to air membrane enthalpy exchanger with six different hybrid flow configurations and the pure cross flow configuration. The moisture diffusion resistance, the water contact angle and the modulus of elasticity of five porous membranes were first evaluated. An experimental setup was then developed and used to investigate the performance of the MEE with various mixed-flow configurations and different air flow rates. The results obtained from this work could be used to guide the optimal design of MEEs.

\section{Description of the mixed-flow membrane enthalpy exchanger}

The performance of the MEE is highly dependent on the flow configuration and air velocity [26]. Fig. 1 presents the mixed flow configuration of the MEE that was investigated in this study. It mainly consists of a pure cross flow core and four adjustable headers. The core was constructed with semi-permeable membranes, sealing brackets and upper/lower bases. The inlet and outlet spans of each air stream were identical. The ratio between the inlet span to the span of the membrane, named entrance ratio, can be varied as $1,0.75,0.5$ and 0.25 respectively, as illustrated in Fig. 2. The sealing brackets and bases were made of acrylic with a thickness of $2 \mathrm{~mm}$ and $20 \mathrm{~mm}$, respectively. The membranes and sealing brackets were assembled together using a special glue, and then sandwiched by the upper and lower bases to form six channels. The headers were connected to the core using flanges. The MEE was insulated by polyester with a thickness of $15 \mathrm{~mm}$ applied to all the external surfaces. 

specified in the test procedure of BS EN 308:1997 standard [27]. The moisture leakage to the surrounding was neglected since the acrylic is strongly impermeable to water vapour.
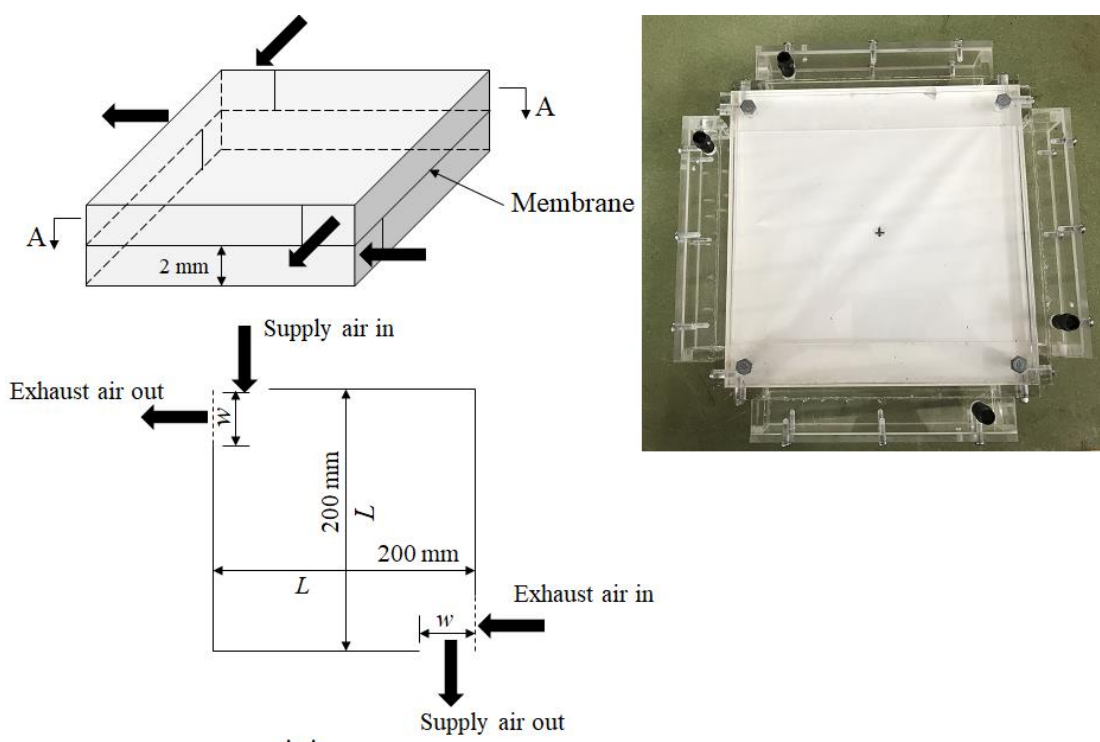

Fig. 1 Schematic of the mixed-flow membrane enthalpy exchanger.

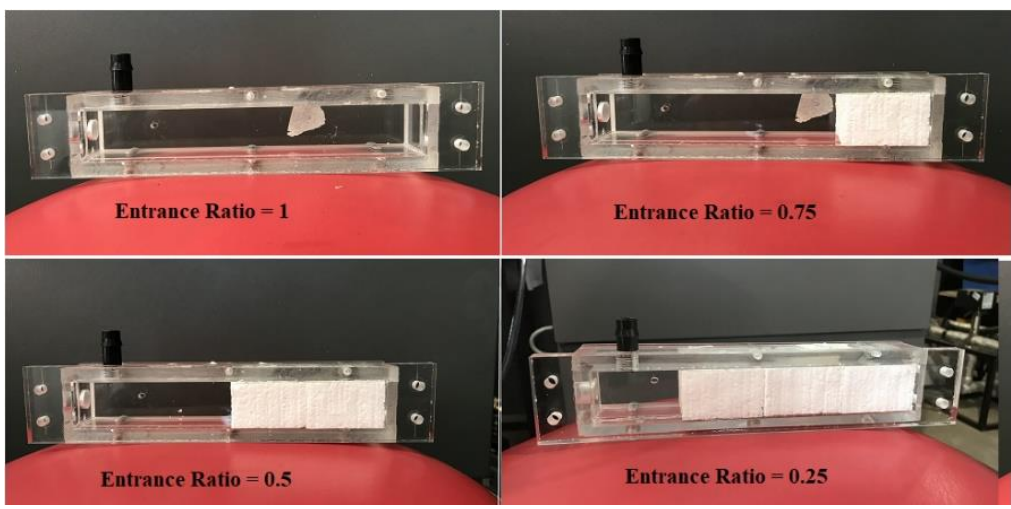

Fig. 2 Illustration of the exchanger headers with four different entrance ratios.

\section{Experimental methodology}

The overall method used in this study is illustrated in Fig. 3. It mainly consists of four

117 steps including i) membrane selection and characterisation; ii) development of the test facility; 

evaluation. They are briefly described as follows.

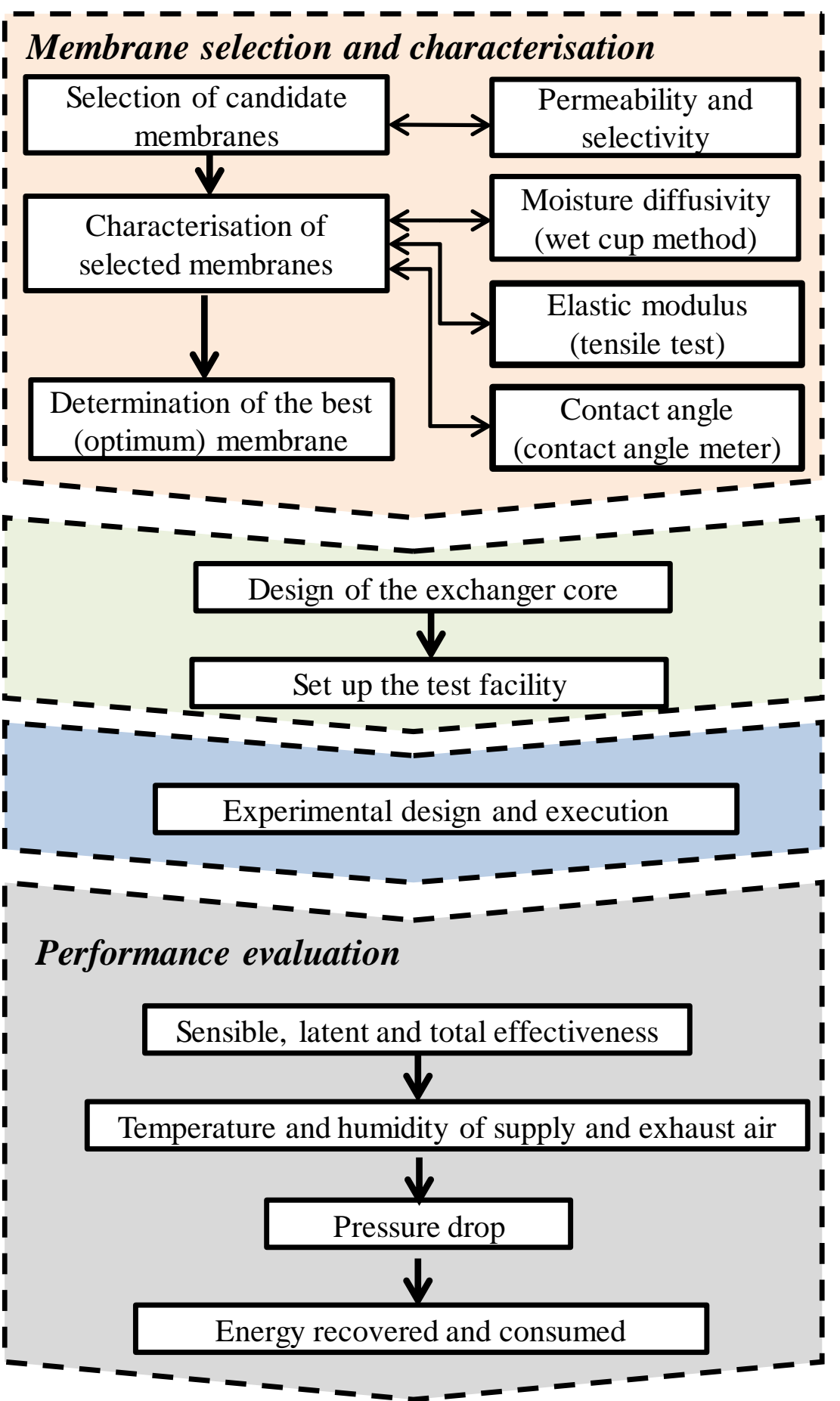

Fig. 3 Outline of the research method. 

pressure difference is relatively small between the exhaust and supply air streams. In addition, the membrane must limit the diffusion of unwanted gases [28]. For this reason, five candidate porous membranes namely (i) Polyvinylidene fluoride (PVDF) membrane with the pore sizes of 0.22 and $0.45 \mu \mathrm{m}$, respectively; (ii) Nylon membrane with the pore sizes of 0.1 and 0.45 $\mu \mathrm{m}$, respectively; and (iii) Polyethersulfone (PES) membrane with a $0.1 \mu \mathrm{m}$ pore size, were initially selected based on the data of the permeability and selectivity of water vapour over the non-desirable gases (i.e. $\mathrm{CO}_{2}$ and $\mathrm{N}_{2}$ ) reported in the previous studies as listed in Table 1 . The selected membranes were then characterised by measuring the moisture diffusivity, water contact angle and elastic modulus to determine the membrane that will be used to fabricate the exchanger core.

Table 1 Permeability and selectivity data for the selected membranes

\begin{tabular}{|c|c|c|c|c|c|c|c|c|}
\hline \multirow[t]{2}{*}{ Membrane } & \multicolumn{6}{|c|}{ Permeability (Barrer ${ }^{\mathrm{a}}$ ) } & \multicolumn{2}{|l|}{ Selectivity } \\
\hline & $\mathrm{H}_{2} \mathrm{O}$ & Ref. & $\mathrm{CO}_{2}$ & Ref & $N_{2}$ & Ref & $\mathrm{H}_{2} \mathrm{O} / \mathrm{CO}_{2}$ & $\mathrm{H}_{2} \mathrm{O} / \mathrm{N}_{2}$ \\
\hline Nylon & 275 & [29] & 0.088 & {$[30]$} & 0.025 & [29] & 3125 & 11000 \\
\hline PES & 2620 & [29] & 3.38 & [31] & 0.25 & [29] & 775 & 10480 \\
\hline PVDF22 & 8542813 & {$[32]$} & 3846 & [33] & 160 & [33] & 2221 & 53393 \\
\hline PVDF45 & 11329341 & {$[32]$} & 3846 & [33] & 160 & [33] & 2946 & 70808 \\
\hline
\end{tabular}

${ }^{\mathrm{a}} 1$ Barrer $=1 \times 10^{-10} \mathrm{~cm}^{3}(\mathrm{STP}) \mathrm{cm} / \mathrm{cm}^{2} \mathrm{~s} \mathrm{~cm} \mathrm{Hg}=7.5005 \times 10^{-18} \mathrm{~m}^{2} \mathrm{~s}^{-1} \mathrm{~Pa}^{-1}$

\subsubsection{Moisture diffusivity measurement}

The wet cup test method introduced in the standard of ASTM E96 [34] was used as the experimental approach to measuring moisture diffusion resistance, and then calculating the moisture diffusivity of the selected membranes. The principle of the wet cup test method is to 
the weight loss of the cup assembly. Fig. 4 illustrates the apparatus of the wet cup test method used in this study. The tests were operated using a PVC cup with a diameter of $90 \mathrm{~mm}$ filled with distilled water. The membrane sample was mounted over the mouth of the cup using flanges. A gasket was applied on the rim to avoid any leakage. The cup assembly was placed in an environmental chamber which can well control the required temperature and humidity.

148 An electronic weighing scale with a resolution of $0.01 \mathrm{~g}$ was used to monitor the weight of the cup assembly during the experiments. The environmental chamber was functioned to maintain the conditions outside of the cup based on the test cases defined in Table 2. The relative humidity inside the cup can be considered as $100 \%$ while the temperature inside the cup was assumed to be the same as the temperature of the environment chamber. The uncertainties of the temperature and relative humidity sensors used were $0.1{ }^{\circ} \mathrm{C}$ and $1 \%$, respectively.

Table 2 Test conditions for the moisture diffusivity measurements

\begin{tabular}{llllllllll}
\hline Test No. & T1 & T2 & T3 & T4 & T5 & T6 & T7 & T8 & T9 \\
\hline Temperature $\left({ }^{\circ} \mathrm{C}\right)$ & 27.5 & 30.0 & 32.5 & 27.5 & 30.0 & 32.5 & 27.5 & 30.0 & 32.5 \\
Relative humidity $(\%)$ & 80 & 80 & 80 & 50 & 50 & 50 & 30 & 30 & 30 \\
\hline
\end{tabular}

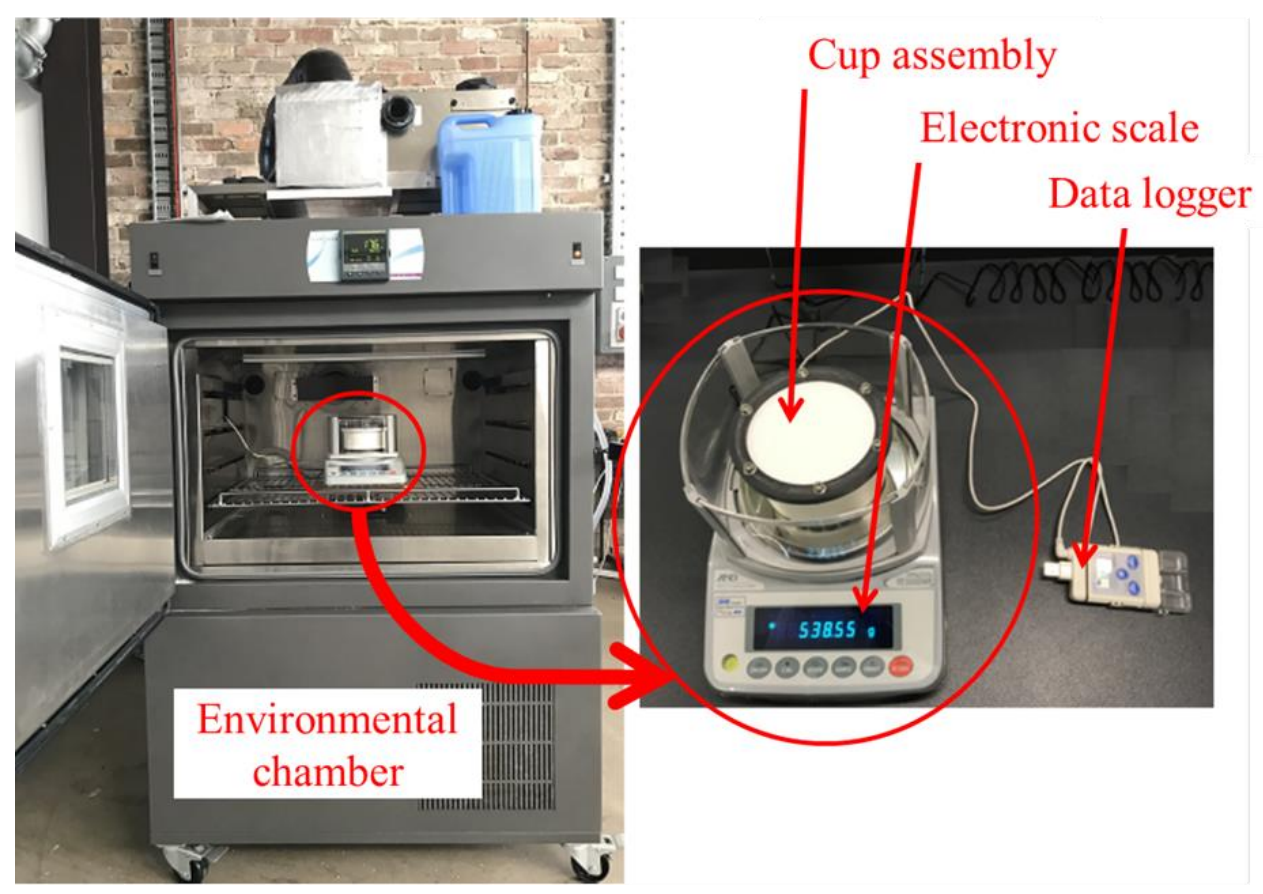

Fig. 4 Test apparatus of the wet cup method. 
The water contact angle (CA) of each tested membrane was measured using a contact angle meter (CAST3, KINO, USA) with an accuracy of $\pm 3^{\circ}$. CAST®3.0 software for drop shape analysis was implemented to analyse the wetting behaviour of the five porous membranes.

\subsubsection{Elastic modulus measurement}

The tensile tests were conducted for the five selected membranes using a Shimadzu EZ-

$\mathrm{S}$ universal test device. The tensile specimens were prepared by cutting the membranes into the rectangular strips with approximate dimensions of $120 \mathrm{~mm} \times 10 \mathrm{~mm}$. The specimens were attached to the test device with the screw loaded clamps. The height of the specimen between the top and bottom clamps was maintained at $100 \mathrm{~mm}$ for all tests. It is worth noting that the nominal thickness of all the tested membranes was $100 \mu \mathrm{m}$. The tests were then undertaken using a $500 \mathrm{~N}$ load cell and the samples were strained at a rate of $1 \mathrm{~mm} / \mathrm{min}$ until the failure occurred. The tensile stress was calculated based on the applied load and the average crosssectional area. The strain was determined using the original length of the unstrained samples. Based on the recorded data, the corresponding stress-strain curves can be generated and used to determine the elastic modulus of the tested membranes. For each type of the membranes, the tests were repeated for three times and the standard errors were estimated by using one standard deviation method.

\subsection{Development of the experimental test facility}

Based on the optimal membrane identified in the first step, the enthalpy exchanger core as presented in Section 2 was constructed. An experimental setup, as illustrated in Fig. 5, was then developed to evaluate the hydrodynamic and thermal performance of the mixed-flow 
experimental setup mainly consists of a MEE core, two environmental chambers, a vacuum pump, connecting pipes and measurement instruments.

The experimental setup was designed as a closed loop system. The air in the two air streams was conditioned in the two environmental chambers at the desired conditions and then supplied to the test MEE core. The air vacuum pump was used to recirculate the outlet air to the environmental chamber. The connecting pipes between the test section and the environmental chamber were insulated to minimise any potential heat loss. Four T-type thermocouples were calibrated and mounted at the inlets and outlets of the exchanger to measure the air temperatures. Two variable area flow meters (Dwyer, RMC-103-SSV) equipped with a control valve were installed at the exits of each air stream of the exchanger respectively to measure the air flow rates. The scale range of the air flow meters used was 10100 1/min. Four Vaisala humidity transmitters (HM110) were installed at the inlets and outlets of the MEE to monitor the relative humidity at each air stream. The pressure drop across the exchanger was measured by a Testo850 differential pressure gauge. During the experiments,

197 the temperature, relative humidity, pressure drop and flow rate of each air stream at the inlet and outlet of the test section were measured every 5 minutes. 


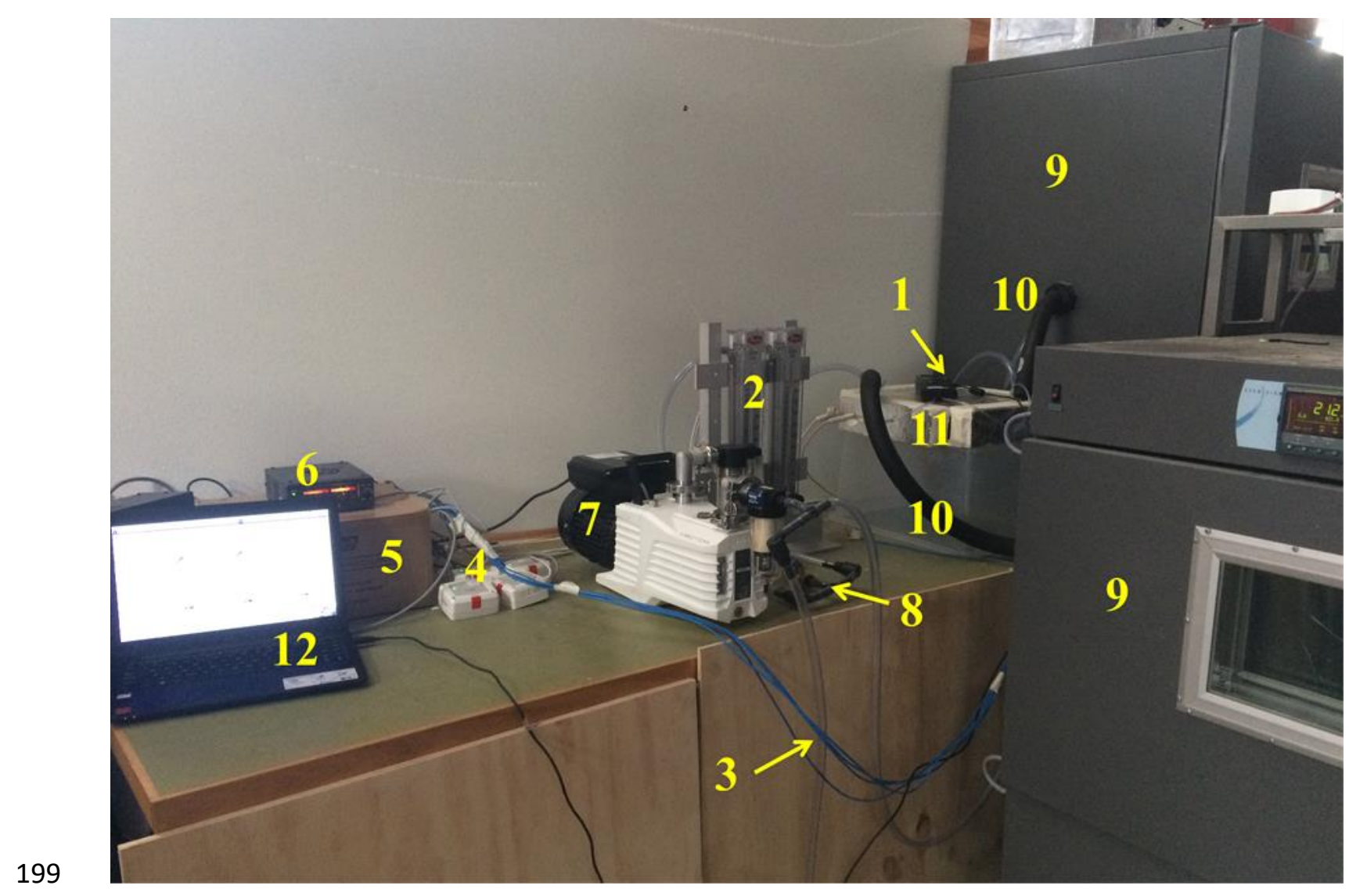

Fig. 5 Experimental test setup (1- differential pressure gauge; 2- air flow meter: 3thermocouples; 4- humidity sensors; 5- data logger in the box; 6- power supply; 7- vacuum pump; 8- control valve; 9- environmental chamber; 10- connecting pipes; 11 - exchanger core; 12- computer). 


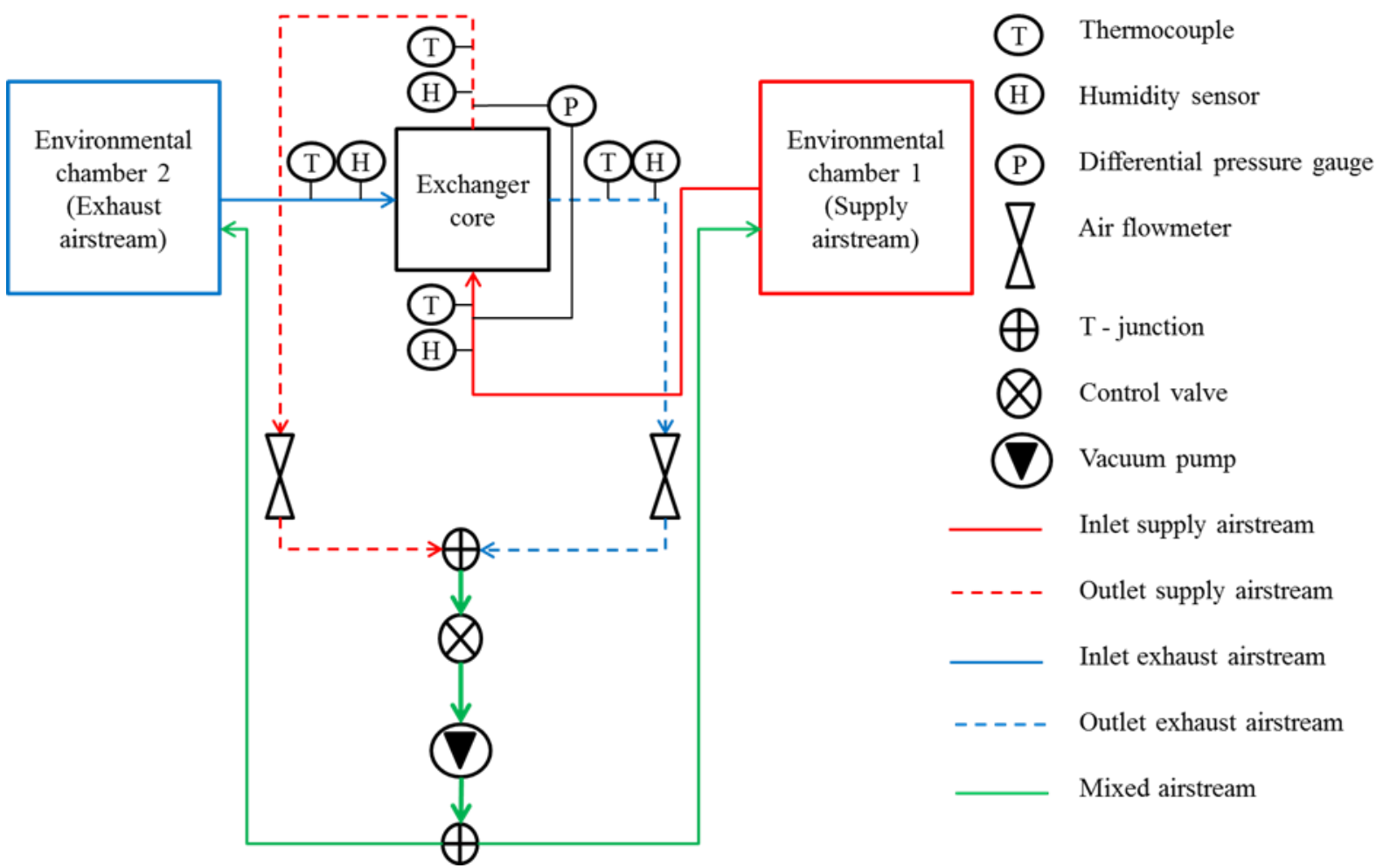

Fig. 6 Simplified schematic of the experimental test setup for the mixed-flow MEE.

3.3 Experimental design and execution

A total of 28 experimental cases were designed and carried out based on the test module of the mixed-flow MEE introduced in Section 2 to examine the performance of the MEE with various mixed-flow configurations. The tests were conducted under four different air flow rates (i.e. 0.3, 0.6, 0.9, $1.2 \mathrm{l} / \mathrm{s}$ ). As summarized in Table 3, seven air flow patterns were investigated in order to determine the best flow configuration. Fig. 7 illustrates the flow configurations of the seven cases listed in Table 3. In each experiment, the flow rates of the two air streams were maintained the same in order to reduce the pressure difference on the membrane sides. In the flow configurations of Case 1-Case 3 and Case 7, the same entrance ratios for both air streams were used. However, different entrance ratios for both air streams were used for the flow configurations of Case 4-Case 6. All the test cases were conducted based on the same inlet air conditions, that is, the inlet temperature and relative humidity of the exhaust stream were 25 ${ }^{\circ} \mathrm{C}$ and $\mathrm{RH} 45 \%$, while those of the supply stream were $35^{\circ} \mathrm{C}$ and $70 \% \mathrm{RH}$, respectively. 
Table 3 Summary of the flow configurations investigated

\begin{tabular}{cccccc}
\hline Configurations & \multicolumn{2}{c}{ Supply channel } & \multicolumn{2}{c}{ Exhaust channel } & Flow pattern \\
\cline { 2 - 5 } & $\begin{array}{c}\text { Entrance } \\
\text { ratio }\end{array}$ & Flow shape & $\begin{array}{c}\text { Entrance } \\
\text { ratio }\end{array}$ & Flow shape & \\
\hline Case 1 & $25 \%$ & Z- shape & $25 \%$ & И- shape & Hybrid flow \\
Case 2 & $50 \%$ & Z- shape & $50 \%$ & И- shape & Hybrid flow \\
Case 3 & $75 \%$ & Z- shape & $75 \%$ & И- shape & Hybrid flow \\
Case 4 & $25 \%$ & Z- shape & $100 \%$ & Straight & Hybrid flow \\
Case 5 & $50 \%$ & Z- shape & $100 \%$ & Straight & Hybrid flow \\
Case 6 & $75 \%$ & Z- shape & $100 \%$ & Straight & Hybrid flow \\
Case 7 & $100 \%$ & Straight & $100 \%$ & Straight & Pure cross flow \\
\hline
\end{tabular}
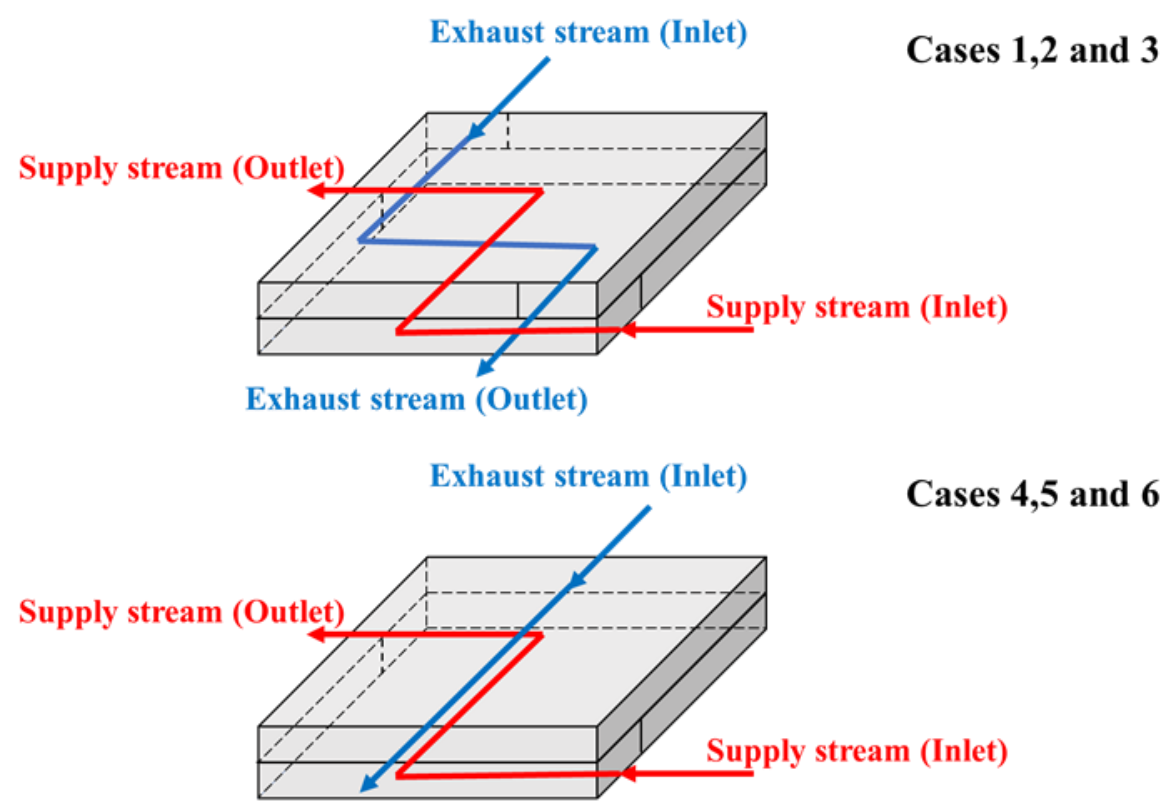

Exhaust stream (Outlet)

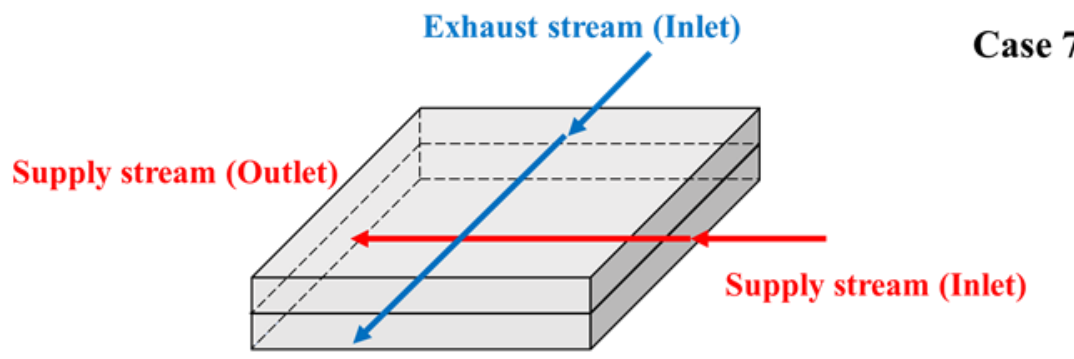

Exhaust stream (Outlet)

Fig.7 Flow configurations of the seven investigated cases.

3.4 Data analysis

The vapour transmission rate $(J)$ across the membrane was calculated by Eq. (1). The

227 corrections for the air gap and the surface resistance were performed using the methods detailed 
in the standard [34]. The vapour transmission rate can also be represented as Eq. (2) [35]. The

229 moisture diffusivity $\left(D_{m}\right)$ was calculated using Eq. (3). The sensible, latent and total

230 effectiveness can be calculated by using Eqs. (4), (5) and (6), respectively [36, 37]. The

231 convective heat and mass transfer coefficients were calculated by Eqs. (7)-(12) [38]. The

232 hydraulic diameter, Nusselt number and Sherwood number were calculated by Eqs. (13), (14)

233 and (15), respectively [39]. The total energy recovered (TER) was calculated by Eq. (16) [26]

234 and the fan power consumption $(P c)$ is determined by Eq. (17) [37], based on the pressure drop

235 measured by the differential pressure gauge.

$236 \quad J=\frac{G}{t A_{c}}$

$237 \quad J=\frac{w_{\text {in }}-w_{\text {out }}}{R_{m}}$

$$
D_{m}=\frac{1}{R_{m} \rho_{a}}
$$

239

$$
\varepsilon_{S}=\frac{m_{S}\left(T_{s i}-T_{S o}\right)+m_{e}\left(T_{e o}-T_{e i}\right)}{2 m_{\min }\left(T_{s i}-T_{e i}\right)}
$$

$$
\varepsilon_{l}=\frac{m_{s}\left(w_{s i}-w_{s o}\right)+m_{e}\left(w_{e o}-w_{e i}\right)}{2 m_{\min }\left(w_{s i}-w_{e i}\right)}
$$

$$
\varepsilon_{t}=\frac{m_{s}\left(h_{s i}-h_{s o}\right)+m_{e}\left(h_{e o}-h_{e i}\right)}{2 m_{\min }\left(h_{s i}-h_{e i}\right)}
$$

$$
h_{\text {heat }}=\frac{\rho_{a} Q_{s} c p \Delta T_{m}}{A_{t} \Delta T_{l m}}
$$

$\Delta T_{m}=\frac{\left(T_{s i}-T_{s o}\right)+\left(T_{e o}-T_{e i}\right)}{2}$

$$
\begin{array}{ll}
244 & \Delta T_{l m}=\frac{\left(T_{s i}-T_{e o}\right)-\left(T_{s o}-T_{e i}\right)}{\ln \left[\frac{\left(T_{s i}-T_{e o}\right)}{\left(T_{s o}-T_{e i}\right)}\right]} \\
245 & h_{\text {mass }}=\frac{\Delta w_{m}}{\rho_{a} A_{t} w_{l m}} \\
246 & \Delta w_{m}=\frac{\left(w_{s i}-w_{s o}\right)+\left(w_{e o}-w_{e i}\right)}{2} \rho_{a} Q_{S} \\
247 & \Delta w_{l m}=\frac{\left(w_{s i}-w_{e o}\right)-\left(w_{s o}-w_{e i}\right)}{\ln \left[\frac{\left(w_{s i}-w_{e o}\right)}{\left(w_{s o}-w_{e i}\right)}\right]} \\
248 & D_{h}=\frac{4 A_{c s}}{P_{d}}
\end{array}
$$$$
246
$$ 


$$
N u=\frac{h_{\text {heat }} D_{h}}{\lambda}
$$

$$
S h=\frac{h_{\text {masss }} D_{h}}{D_{a}}
$$

$$
T E R=m_{s}\left(h_{s i}-h_{s o}\right)
$$

$$
P c=n Q_{s} \Delta p+n Q_{e} \Delta p
$$

where $J$ is the mass flux across the membrane, $G$ is the weight change of the cup assembly, $t$ is the time during which weight change occurred, $A_{c}$ is the area of the cup, $w_{\text {in }}$ and $w_{\text {out }}$ are the humidity inside and outside of the cup respectively, $R_{m}$ is the moisture diffusion resistance of the membrane, $D_{m}$ is the moisture diffusivity of the membrane, $\rho_{a}$ is the air density, $\varepsilon_{s}, \varepsilon_{l}$ and $\varepsilon_{t}$ are the sensible, latent and total effectiveness respectively, $m$ is the mass flow rate, $T$ is the air temperature, $w$ is the air humidity, $h$ is the specific enthalpy, $h_{\text {heat }}$ is the convective heat transfer coefficient, $Q$ is the volume flow rate, $c p$ is the specific heat, $A_{t}$ is the membrane area, $h_{\text {mass }}$ is the convective mass transfer coefficient, $D_{h}$ is the hydraulic diameter, $A_{c s}$ is the cross section area of the channel, $P_{d}$ is the perimeter of the channel, $N u$ is Nusselt number, $\lambda$ is the air conductivity, $S h$ is Sherwood number, $D_{a}$ is the moisture diffusivity in air, TER is the total energy recovered, $P_{c}$ is the power consumption, $\Delta p$ is the pressure drop across the channel and $n$ is the number of the channels for each air stream.

The uncertainties in the experimental tests can result from the instrument calibration and data acquisition [35]. Uncertainty analysis is essential to evaluating the accuracy of the experiments. The uncertainties of the measured parameters included temperature, relative humidity, flow rate and pressure drop were $\pm 0.1{ }^{\circ} \mathrm{C}, \pm 2 \%, \pm 2 \%$ and $\pm 0.1 \mathrm{~Pa}$, respectively. The uncertainty $(\delta R y)$ of each calculated parameter was estimated using the basic root-sumsquare as given by Eq. (18) [40].

271

$$
\delta R y=\frac{\sqrt{\sum_{i=1}^{m}\left(\frac{\partial y}{x_{i}} \delta x_{i}\right)^{2}}}{y}
$$


where $m$ is the number of the independent parameters, and $y$ is the main parameter dependent on the series of the independent parameters $x_{i}$. The estimated uncertainties were found to be highly dependent on the operating conditions. However, the highest values of the uncertainties for the calculated sensible, latent and total effectiveness were $3.2 \%$ and $5.1 \%, 5.9 \%$, respectively.

\section{Results and discussions}

4.1 Results of the moisture diffusivity measurements

During the practical operation of MEEs, the weather conditions such as temperature and humidity may change continuously. It is therefore important to quantify the influence of those parameters on the moisture transfer across the membrane. Fig. 8 shows the variations in the moisture diffusion resistance of the tested membranes with the test conditions specified in Table 2. It can be seen that all the tested membranes showed similar behaviour against the test conditions. The lowest values of the moisture diffusion resistance were offered by PVDF45 membrane while Nylon10 membrane showed the highest values of the moisture diffusion resistance. The moisture diffusion resistance was insensitive to the test temperature. For instance, for the PVDF45 membrane at RH of $80 \%$ (i.e. test cases of T1-T3 in Table 2), the moisture diffusion resistance changed from 42.3 to $44.8 \mathrm{~m}^{2} . \mathrm{s} / \mathrm{kg}$ when the test temperature increased from 27.5 to $32.5{ }^{\circ} \mathrm{C}$. On the other hand, the relative humidity difference across the membrane slightly influenced the moisture diffusion resistance. For instance, for the PVDF45 membrane at the temperature of $30^{\circ} \mathrm{C}$ (i.e. test cases of $\mathrm{T} 2, \mathrm{~T} 5$ and $\mathrm{T} 8$ in Table 2), the moisture diffusion resistance increased from 43.6 to $46.3 \mathrm{~m}^{2} . \mathrm{s} / \mathrm{kg}$ when the relative humidity outside the cup (i.e. environmental chamber) decreased from $80 \%$ to $30 \%$. The moisture diffusion resistance of the PVDF22 membrane at the test conditions of T7 was similar to that reported in [41]. 


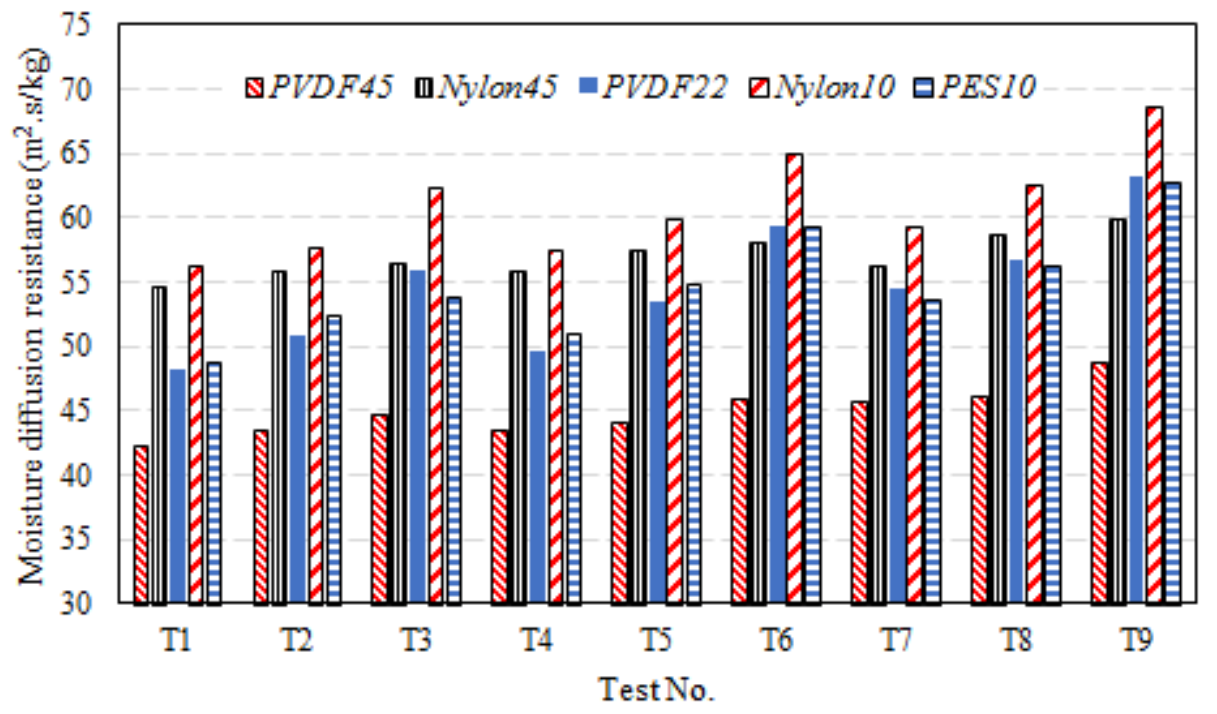

296

297 Fig. 8 Variations in the moisture diffusion resistance under different test conditions for the five membranes tested.

The moisture diffusivity is another parameter that can directly indicate the moisture 300 transfer capacity through the membrane. Fig. 9 illustrates the variation in the moisture 301 diffusivity under different test conditions for the five membranes tested. It can be clearly seen 302 that the test conditions slightly influenced the diffusivity of each membrane. The mean 303 diffusivity values for the tested membranes together with the uncertainty due to the test 304 conditions are provided in Table 4. The maximum value of the mean moisture diffusivity was $3051.91 \times 10^{-6} \pm 2.42 \times 10^{-8} \mathrm{~m}^{2} / \mathrm{s}$ for the PVDF45 membrane, while the lowest value was $1.41 \times 10^{-6}$ $306 \pm 2.71 \times 10^{-8} \mathrm{~m}^{2} / \mathrm{s}$ for the Nylon10 membrane. 


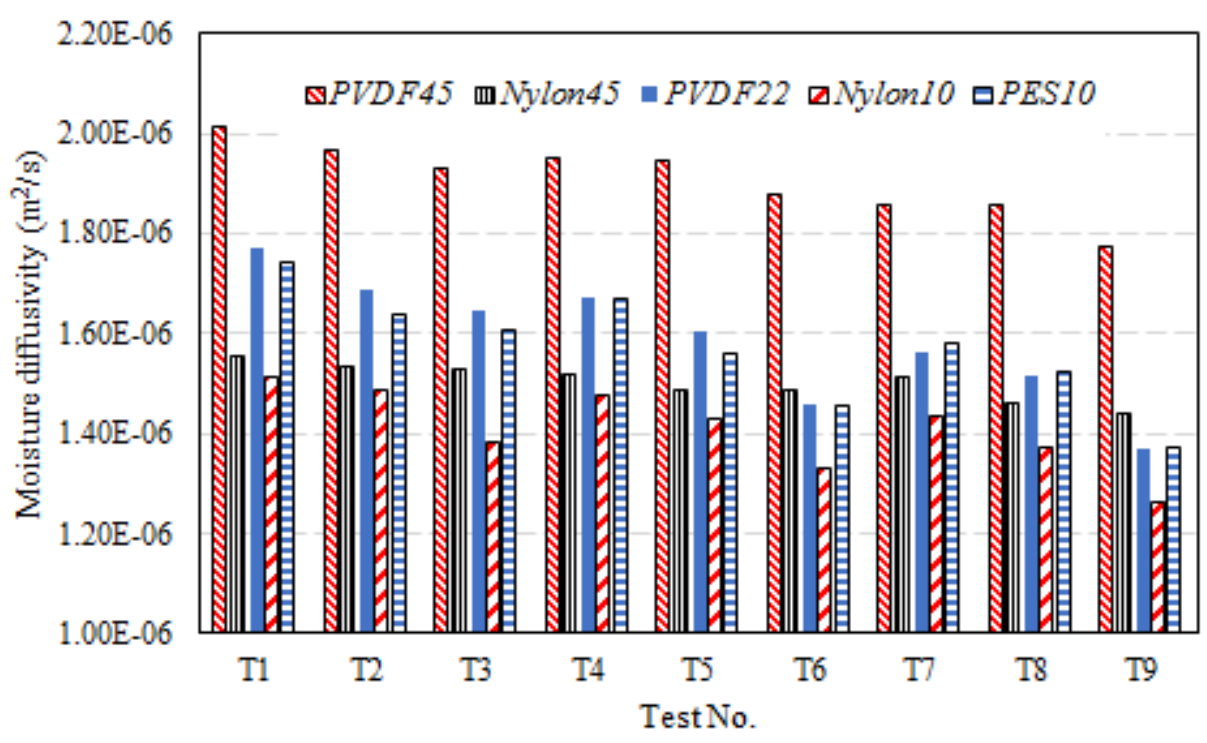

Fig. 9 Variations in the moisture diffusivity under different test conditions for the five membranes tested.

Table 4 Mean moisture diffusivity and calculated uncertainties for the five membranes tested.

\begin{tabular}{lccccc}
\hline Membrane & PVDF45 & Nylon45 & PVDF22 & Nylon10 & PES10 \\
\hline $\begin{array}{l}\text { Moisture } \\
\text { diffusivity }\left(\mathrm{m}^{2} / \mathrm{s}\right)\end{array}$ & $1.91 \times 10^{-6}$ & $1.50 \times 10^{-6}$ & $1.59 \times 10^{-6}$ & $1.41 \times 10^{-6}$ & $1.57 \times 10^{-6}$ \\
$\begin{array}{l}\text { Uncertainties } \\
\left(\mathrm{m}^{2} / \mathrm{s}\right)\end{array}$ & $2.42 \times 10^{-8}$ & $1.23 \times 10^{-8}$ & $4.14 \times 10^{-8}$ & $2.71 \times 10^{-8}$ & $3.71 \times 10^{-8}$ \\
\hline
\end{tabular}

4.2 Results of the contact angles

Fig. 10 shows the water contact angles of the five membranes. The contact angle below than $90^{\circ}$ indicated that the membrane surface was hydrophilic. It can be seen that all the tested membranes were hydrophilic. However, they varied in the degree of hydrophilicity based on

317 the contact angle. The PVDF22 membrane yielded the highest average contact angle of $76.2^{\circ}$ while Nylon45 membrane exhibited the lowest average contact angle of $40.5^{\circ}$. 

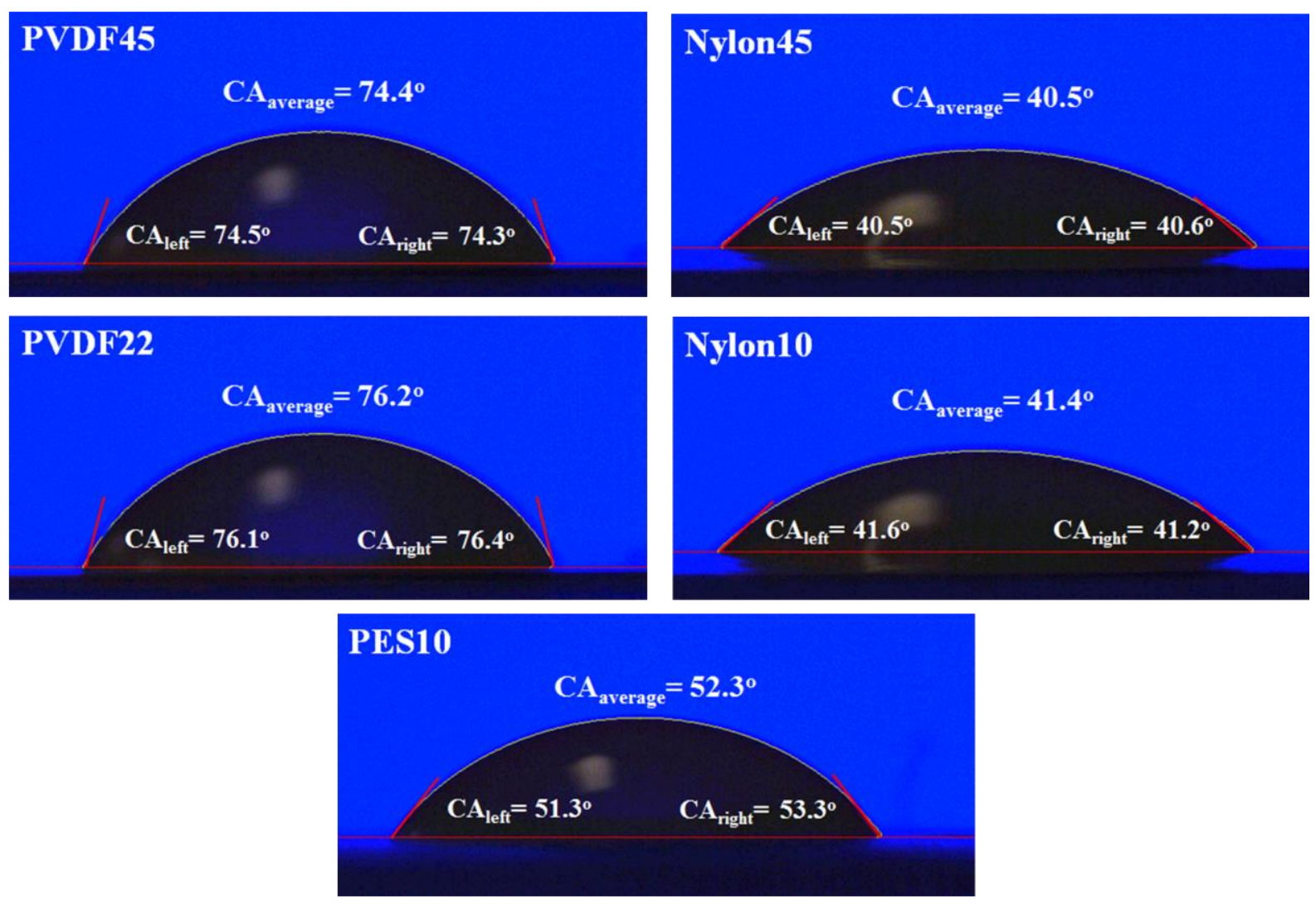

Fig. 10 Water contact angles for the tested membranes.

4.3 Results of elastic modulus measurements

The stress-strain curve is usually used to identify the mechanical properties of engineering materials. In this study, the tensile stress-strain curves of the five membranes tested are illustrated in Fig. 11. These stress-strain curves were used to determine the tensile properties including tensile strength, failure strain and modulus of elasticity (Young's modulus). The membrane PVDF22 showed the highest tensile strength of $1.81 \times 10^{7} \mathrm{MPa}$, while the membrane PES10 showed the lowest value $\left(1.35 \times 10^{6} \mathrm{MPa}\right)$. The failure strain of the membranes PVDF22, Nylon10 and Nylon45 were around $0.08 \mathrm{~mm} / \mathrm{mm}$ and they are very close to each other. The membrane PVDF45 had the maximum failure strain at around $0.12 \mathrm{~mm} / \mathrm{mm}$.

Table 5 summarises the mechanical properties of the five membranes tested. The properties including tensile strength, failure strain and the average values of the elastic modulus with the errors determined by the standard deviation for all the measurements. The elastic 
modulus for the PES10 was significantly lower than those for the other membranes. In addition, small differences were observed amongst the values of the elastic modulus of the PVDF22, Nylon10 and PVDF45 which were around $500 M P a$.

As a summary, among the membranes tested, the PVDF45 membrane yielded the highest value of the mean moisture diffusivity. PVDF22, Nylon10 and PVDF45 membranes showed relatively high values of elastic modulus with small differences amongst them. Therefore, the PVDF45 membrane was selected to fabricate the membrane enthalpy exchanger core.

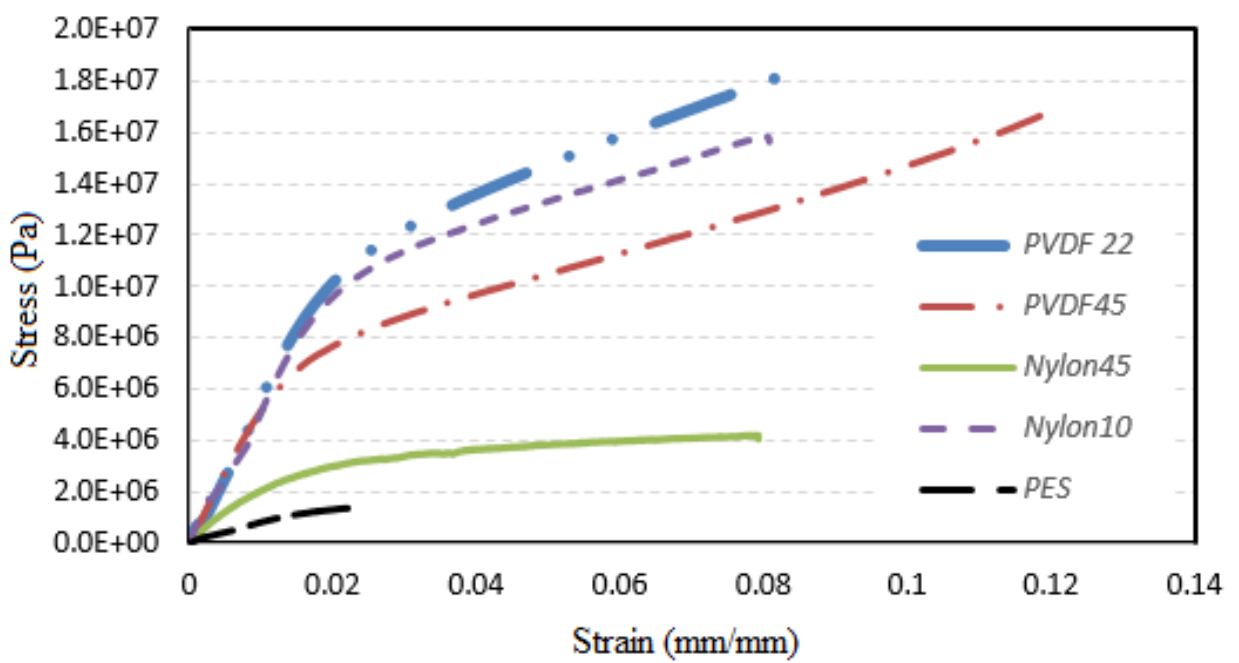

341

Fig. 11 Stress-strain curves of the five tested membranes.

Table 5 Mechanical properties of the five tested membranes

\begin{tabular}{llllll}
\hline Membrane & PVDF45 & Nylon45 & PVDF22 & Nylon10 & PES10 \\
\hline Tensile strength (MPa) & $1.67 \times 10^{7}$ & $4.20 \times 10^{6}$ & $1.81 \times 10^{7}$ & $1.58 \times 10^{7}$ & $1.35 \times 10^{6}$ \\
Failure strain (mm/mm) & $11.94 \%$ & $7.92 \%$ & $8.16 \%$ & $8.06 \%$ & $2.32 \%$ \\
Elastic Modulus (MPa) & $4.97 \times 10^{8}$ & $1.89 \times 10^{8}$ & $5.20 \times 10^{8}$ & $5.16 \times 10^{8}$ & $7.67 \times 10^{7}$ \\
Uncertainties (MPa) & $3.86 \times 10^{7}$ & $1.94 \times 10^{7}$ & $1.86 \times 10^{7}$ & $1.63 \times 10^{7}$ & $2.03 \times 10^{6}$ \\
\hline
\end{tabular}


performance, hydrodynamic performance and energy performance.

4.4.1 Thermal performance

The temperature and humidity were presented in order to examine the influence of the hybrid configurations on the outlet air properties of each air stream. The temperature and humidity of the outlet air in both supply and exhaust channels are provided in Table 6 . and flow configurations

\begin{tabular}{ccccccccccc}
\hline \multirow{2}{*}{\multicolumn{2}{c}{ Case }} & \multicolumn{3}{c}{ Flow rate $(\mathrm{l} / \mathrm{s})$} & & \multicolumn{4}{c}{ Flow rate $(\mathrm{l} / \mathrm{s})$} \\
\cline { 2 - 10 } & & 0.3 & 0.6 & 0.9 & 1.2 & & 0.3 & 0.6 & 0.9 & 1.2 \\
\hline \multirow{2}{*}{1} & $T_{e o}\left({ }^{\circ} \mathrm{C}\right)$ & 34.1 & 33.5 & 33.0 & 32.4 & $w_{e o}(\mathrm{~g} / \mathrm{kg})$ & 25.88 & 24.68 & 23.57 & 22.51 \\
& $T_{s o}\left({ }^{\circ} \mathrm{C}\right)$ & 25.8 & 26.4 & 26.9 & 27.4 & $w_{s o}(\mathrm{~g} / \mathrm{kg})$ & 11.87 & 13.00 & 14.08 & 15.09 \\
\multirow{2}{*}{2} & $T_{e o}\left({ }^{\circ} \mathrm{C}\right)$ & 33.9 & 33.3 & 32.9 & 32.4 & $w_{e o}(\mathrm{~g} / \mathrm{kg})$ & 25.55 & 24.31 & 23.35 & 22.48 \\
& $T_{s o}\left({ }^{\circ} \mathrm{C}\right)$ & 26.0 & 26.5 & 27.0 & 27.5 & $w_{s o}(\mathrm{~g} / \mathrm{kg})$ & 12.13 & 13.29 & 14.36 & 15.18 \\
\multirow{2}{*}{3} & $T_{e o}\left({ }^{\circ} \mathrm{C}\right)$ & 33.7 & 33.1 & 32.6 & 32.2 & $w_{e o}(\mathrm{~g} / \mathrm{kg})$ & 25.17 & 23.88 & 23.07 & 22.24 \\
& $T_{s o}\left({ }^{\circ} \mathrm{C}\right)$ & 26.2 & 26.7 & 27.4 & 27.7 & $w_{s o}(\mathrm{~g} / \mathrm{kg})$ & 12.46 & 13.62 & 14.77 & 15.52 \\
\multirow{2}{*}{4} & $T_{e o}\left({ }^{\circ} \mathrm{C}\right)$ & 33.5 & 33.0 & 32.5 & 32.0 & $w_{e o}(\mathrm{~g} / \mathrm{kg})$ & 24.91 & 23.80 & 22.79 & 21.92 \\
& $T_{s o}\left({ }^{\circ} \mathrm{C}\right)$ & 26.2 & 26.8 & 27.5 & 28.0 & $w_{s o}(\mathrm{~g} / \mathrm{kg})$ & 12.53 & 13.79 & 14.96 & 15.98 \\
\multirow{2}{*}{5} & $T_{e o}\left({ }^{\circ} \mathrm{C}\right)$ & 33.4 & 32.7 & 32.3 & 31.8 & $w_{e o}(\mathrm{~g} / \mathrm{kg})$ & 24.62 & 23.17 & 22.27 & 21.51 \\
& $T_{s o}\left({ }^{\circ} \mathrm{C}\right)$ & 26.3 & 26.9 & 27.5 & 27.9 & $w_{s o}(\mathrm{~g} / \mathrm{kg})$ & 12.59 & 13.81 & 14.85 & 15.75 \\
\multirow{2}{*}{6} & $T_{e o}\left({ }^{\circ} \mathrm{C}\right)$ & 33.3 & 32.8 & 32.4 & 31.9 & $w_{e o}(\mathrm{~g} / \mathrm{kg})$ & 24.49 & 23.34 & 22.35 & 21.79 \\
& $T_{s o}\left({ }^{\circ} \mathrm{C}\right)$ & 26.4 & 26.9 & 27.7 & 28.1 & $w_{s o}(\mathrm{~g} / \mathrm{kg})$ & 12.72 & 13.97 & 15.14 & 16.25 \\
\multirow{2}{*}{7} & $T_{e o}\left({ }^{\circ} \mathrm{C}\right)$ & 33.2 & 32.7 & 32.0 & 31.5 & $w_{e o}(\mathrm{~g} / \mathrm{kg})$ & 23.50 & 22.30 & 21.31 & 20.70 \\
& $T_{s o}\left({ }^{\circ} \mathrm{C}\right)$ & 26.9 & 27.2 & 27.8 & 28.2 & $w_{s o}(\mathrm{~g} / \mathrm{kg})$ & 13.70 & 14.61 & 15.30 & 16.00 \\
\hline
\end{tabular}

As expected, the increase in the flow rate resulted in the increase in the outlet air temperature and humidity of the supply air stream and the decrease in the outlet air temperature and humidity for the exhaust air stream. The temperature and humidity followed the same for the exhaust air side and from 25.8 to $28.2{ }^{\circ} \mathrm{C}$ for the supply air side, while the outlet air humidity changed from 25.88 to $20.70 \mathrm{~g} / \mathrm{kg}$ for the exhaust channel and from 11.87 to 16.00 $\mathrm{g} / \mathrm{kg}$ for the supply channel. For the exhaust air stream, the highest temperature and humidity 
were found to be $34.1{ }^{\circ} \mathrm{C}$ and $25.88 \mathrm{~g} / \mathrm{kg}$ respectively in Case 1 at the flow rate of $0.3 \mathrm{l} / \mathrm{s}$, while the lowest values of the temperature and humidity were $31.5^{\circ} \mathrm{C}$ and $20.70 \mathrm{~g} / \mathrm{kg}$ in Case 7 at the flow rate of $1.2 \mathrm{l} / \mathrm{s}$. In the supply channels, the trends were opposite as the lowest temperature $\left(25.8^{\circ} \mathrm{C}\right)$ and humidity $(11.87 \mathrm{~g} / \mathrm{kg})$ were observed in Case 1 at the flow rate of $0.3 \mathrm{l} / \mathrm{s}$, and the highest values $\left(28.2{ }^{\circ} \mathrm{C}, 16.00 \mathrm{~g} / \mathrm{kg}\right)$ were found in Case 7 at the flow rate of $1.2 \mathrm{l} / \mathrm{s}$.

The variations of the sensible, latent and total effectiveness with the change of the flow rate for the investigated configurations are presented in Fig. 12. It can be seen that the flow rate had a significant impact on the sensible, latent and total effectiveness, which all were inversely proportional to the increase of the flow rate. This is because the flow resident time inside the exchanger decreased with the increasing flow rate. The variations of the effectiveness of the hybrid configurations were relatively more noticeable than that for the pure cross flow configuration. For example, the total effectiveness of Case 1 decreased from $89.3 \%$ to $71.5 \%$ as the flow rate increased from $0.3 \mathrm{l} / \mathrm{s}$ to $1.2 \mathrm{l} / \mathrm{s}$. In the meanwhile, the total effectiveness of Case 7 (i.e. pure cross flow) varied from $77.9 \%$ to $63.7 \%$ (Fig. 12c). effectiveness were similar. However, the sensible effectiveness was the highest among the three effectiveness under the same flow configuration and flow rate, whilst the latent effectiveness was the lowest one as the mass diffusivity was higher than the thermal diffusivity. The maximum values of the sensible, latent and total effectiveness were $91.2 \%, 88.9 \%$ and $89.3 \%$ respectively at Case 1 when the flow rate was $0.3 \mathrm{l} / \mathrm{s}$. However, the lowest values of the three effectiveness were $66.45 \%, 63.1 \%$ and $63.67 \%$ respectively at Case 7 (i.e. pure cross flow) when the flow rate was $1.2 \mathrm{l} / \mathrm{s}$.

It can be also seen that the hybrid cases showed a better effectiveness as compared to the pure cross flow. However, the performance enhancement was more obvious in the identical entrance ratio cases (i.e. Cases 1, 2, 3) and the effectiveness increased as the entrance ratio 
389 decreased. For instance, the sensible, latent and total effectiveness of Case 1 increased by $39012.3 \%, 15.1 \%$ and $14.6 \%$ respectively when the flow rate was $0.3 \mathrm{l} / \mathrm{s}$ while those values for

391 Case 4 were $6.8 \%, 9.3 \%$ and $8.8 \%$ respectively under the same flow rate, as compared to that 392 of the pure cross flow.

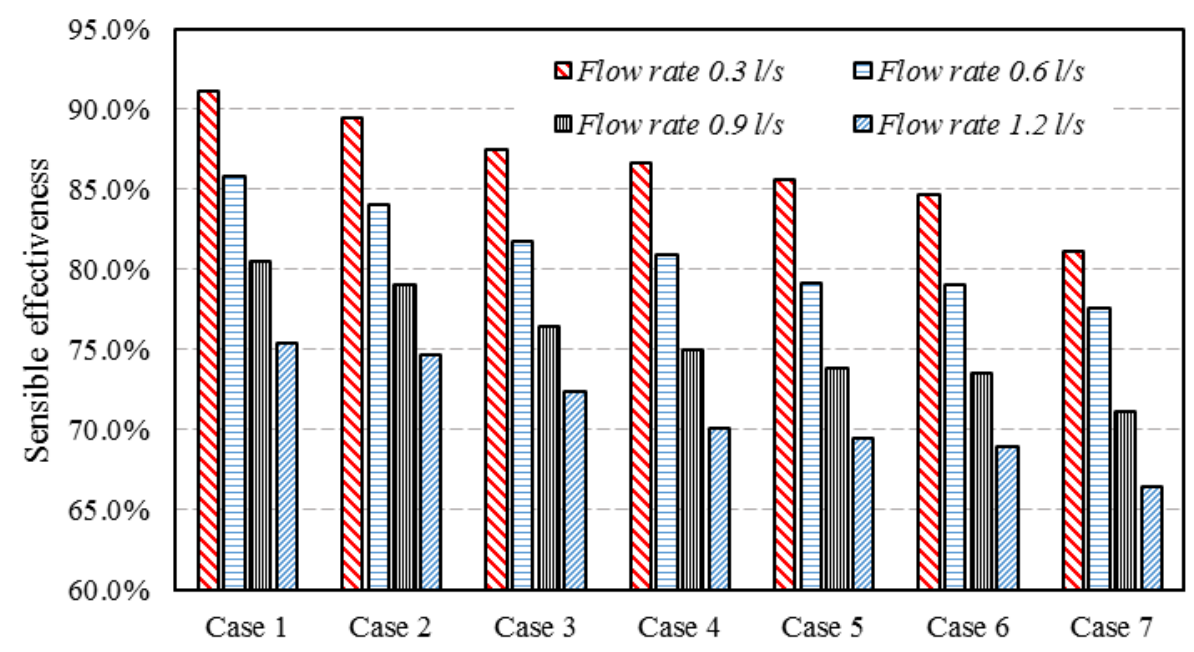

393

a) Sensible effectiveness

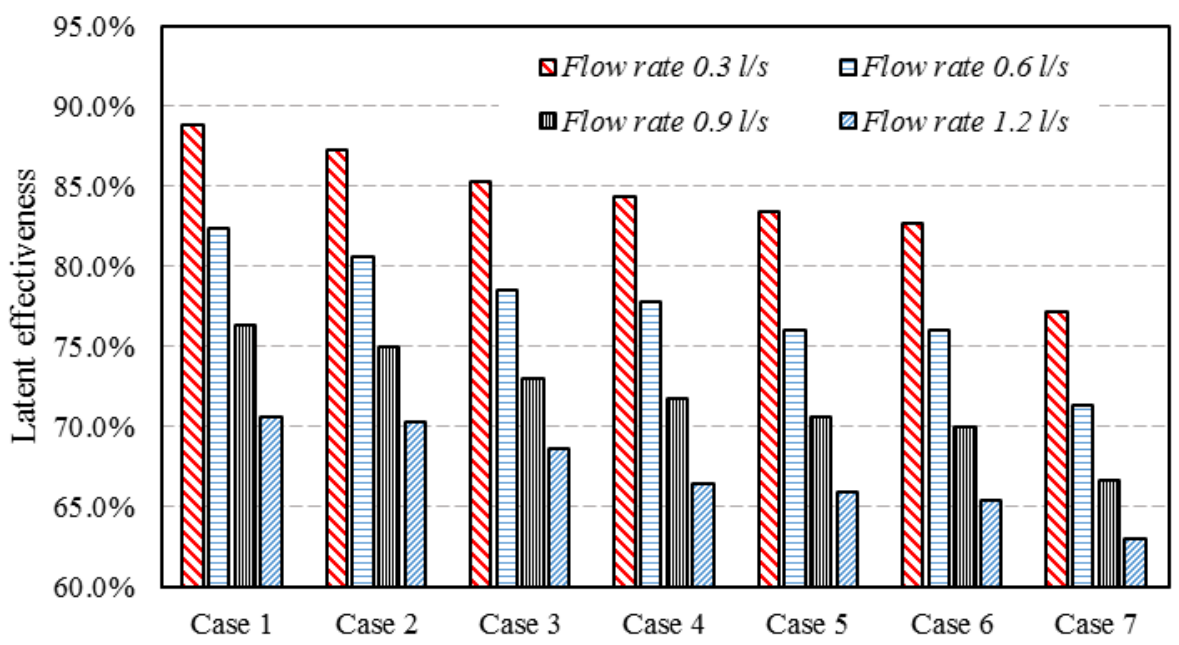

b) Latent effectiveness 


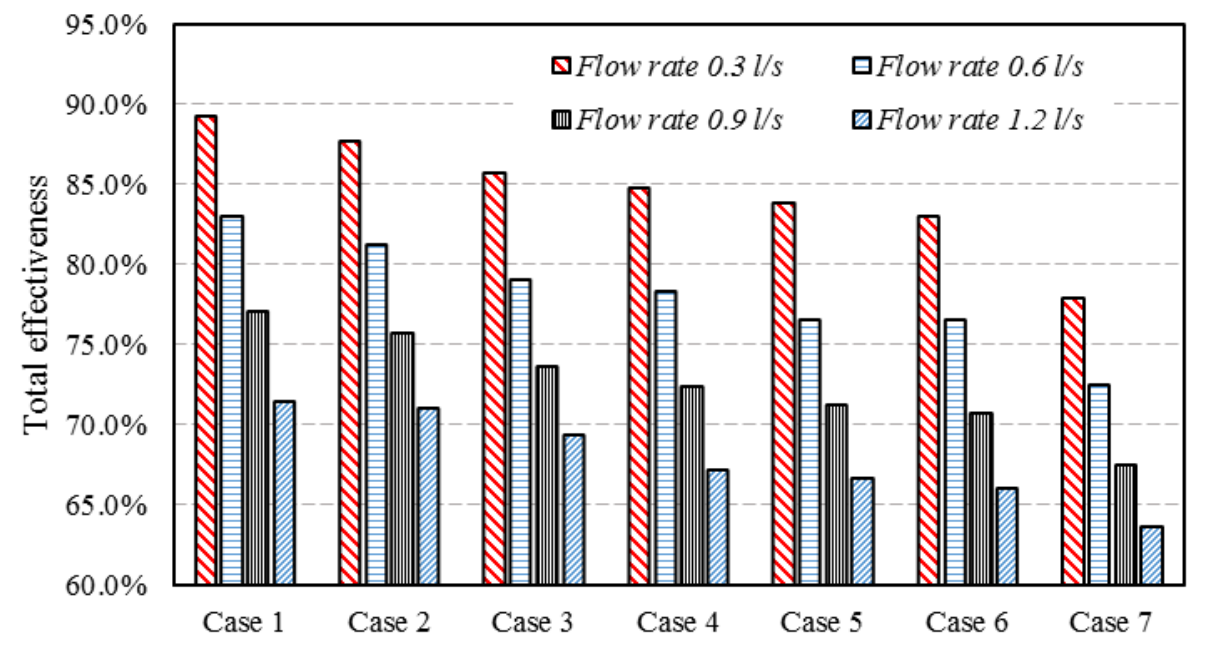

397

c) Total effectiveness

Fig. 12 Variations in the three effectiveness under different flow rates and flow

400

configurations.

401

402 The values of the sensible, latent and total effectiveness obtained for Case7 (i.e. pure cross

403 flow) at the flow rate of $1.2 \mathrm{l} / \mathrm{s}$ were compared to the results reported in literature [42]. The

404 operating conditions and the exchanger specifications of the current study and the previous study are summarised in Table 7. The sensible, latent and total effectiveness of Case 7 in this study were $66.5 \%, 63 \%$ and $63.7 \%$ respectively, while those in [42] were $67 \%, 54.5 \%$ and 57.5 respectively. The comparison showed a good agreement for the sensible effectiveness between the two sets of data as the conductive heat transfer through the membrane can be neglected due to the small membrane thickness [35]. However, both the latent and total effectiveness obtained in this study was different from that in the literature as they highly affected by the membrane properties $[14,15]$. 


\begin{tabular}{l|l|l}
\hline \multicolumn{3}{c}{ Conditions and specification } \\
\hline \multicolumn{1}{c}{ This study } \\
\hline Test conditions & $T_{s i: 3{ }^{\circ} \mathrm{C} ; R H_{s i}: 70 \% ; T_{e i}:}$ & \multicolumn{1}{c}{$T_{s i}: 35^{\circ} \mathrm{C} ; R H_{s i}: 70 \% ; T_{e i}:$} \\
& $25^{\circ} \mathrm{C} ; R H_{e i}: 45 \% ;$ Flow & $2{ }^{\circ} C ; R H_{e i}: 50 \% ;$ Flow rate \\
& rate for single channel: 0.4 & for single channel: $\approx 0.4 l / s$ \\
& $l / s$ & Cross flow \\
\hline Flow configuration & Cross flow & 0.25 \\
Channel length $(\mathrm{m})$ & 0.2 & 0.25 \\
Channel Width $(\mathrm{m})$ & 0.2 & 2 \\
Channel height $(\mathrm{mm})$ & 2 & dense \\
Membrane type & Porous & $\approx 2.17 \times 10^{-7}$ \\
Moisture diffusivity $\left(\mathrm{m}^{2} / \mathrm{s}\right)$ & $1.91 \times 10^{-6}$ & 2.5 \\
Membrane adsorption & - & 0.1 \\
constant & \multicolumn{2}{c}{} \\
Membrane thickness $(\mathrm{mm})$ & 0.1 &
\end{tabular}

Table 7 Summary of the operating conditions and the exchanger specifications of the current study and the previous study.

Conditions and specification
416

417

418 

flow rate conditions.

\begin{tabular}{|c|c|c|c|c|c|c|c|c|c|c|}
\hline & \multicolumn{6}{|c|}{ Flow rate $(l / s)$} & \multicolumn{4}{|c|}{ Flow rate $(l / s)$} \\
\hline Case & & 0.3 & 0.6 & 0.9 & 1.2 & & 0.3 & 0.6 & 0.9 & 1.2 \\
\hline 1 & & 4.76 & 5.62 & 5.74 & 5.76 & & 4.30 & 4.71 & 4.73 & 4.79 \\
\hline 2 & & 3.93 & 4.85 & 5.22 & 5.45 & & 3.60 & 4.12 & 4.34 & 4.51 \\
\hline 3 & & 3.24 & 4.14 & 4.49 & 4.83 & & 2.97 & 3.58 & 3.91 & 4.17 \\
\hline 4 & $\mathrm{Nu}$ & 3.02 & 3.93 & 4.16 & 4.33 & $S h$ & 2.76 & 3.43 & 3.65 & 3.76 \\
\hline 5 & & 2.76 & 3.52 & 3.92 & 4.21 & & 2.56 & 3.09 & 3.45 & 3.67 \\
\hline 6 & & 2.57 & 3.50 & 3.85 & 4.10 & & 2.41 & 3.09 & 3.35 & 3.57 \\
\hline 7 & & 1.99 & 3.20 & 3.42 & 3.66 & & 1.66 & 2.40 & 2.86 & 3.22 \\
\hline
\end{tabular}

433

434

4.4.2 Hydrodynamic performance

The hydrodynamic performance of the exchanger was investigated by determining the pressure drop along the flow channel for different flow configurations and various flow rates (Fig.13). In general, the pressure drop increased with the increase of the flow rate as the shear stress on the membrane surface increased. It can be also observed that the entrance ratio influenced the pressure drop negatively. For a given flow rate, decreasing the entrance ratio

441 resulted in an increase in the flow velocity and generating the vortex zones. The recirculation 442 zones disturbed the flow stream and might turn the flow from laminar into turbulent. The turbulent flow featured with a high boundary layer skin friction can increase the drag, and as a result increased the pressure drop. 


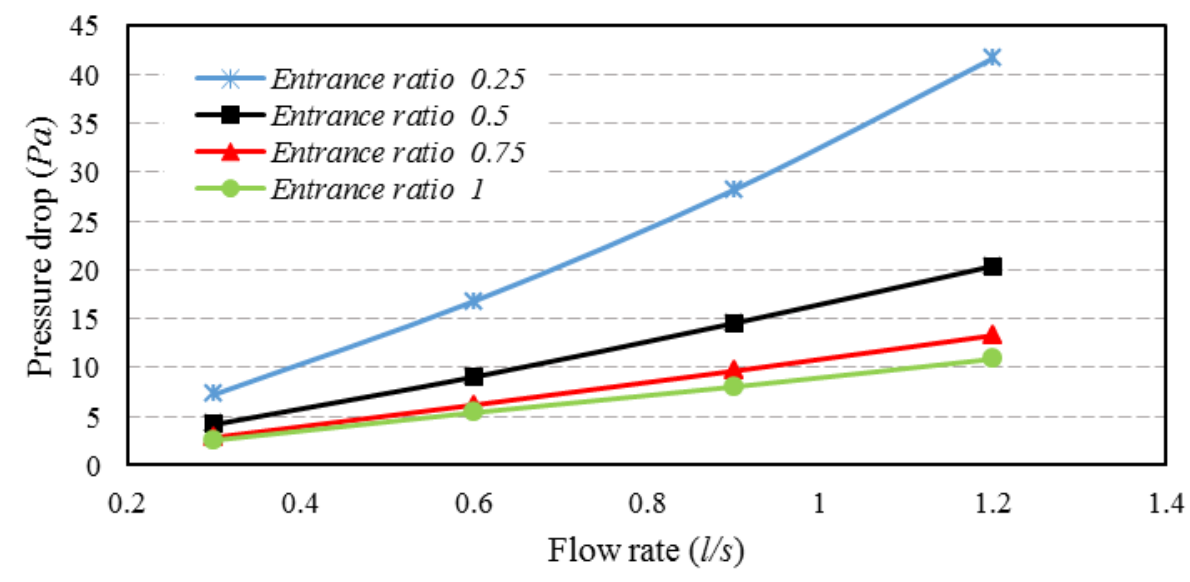

Fig.13 Variations of the pressure drop of mixed-flow channels under various entrance ratios and flow rates.

\subsubsection{Energy performance evaluation}

The energy analysis for the studied MEE was conducted in order to understand the benefit

of the proposed hybrid configurations. This analysis was carried out based on the recovered

451 energy and consumed energy. The consumed energy was mainly due to the fan power

452 consumption. Fig. 14 presents the variations in the total energy recovered with the variation of

453 the flow rates for all investigated flow configurations. The total energy recovered increased

454 with the increase in the flow rate, and the total energy recovered was in the range of 16.2-59.1

$455 W$. The amount of energy recovered by the MEE in Case 1 was $12.8 \%, 11.6 \%, 10.1 \%$ and $8.4 \%$

456 higher under the flow rates of $0.3,0.6,0.9$ and $1.2 \mathrm{l} / \mathrm{s}$ respectively than that of the test case 7

457 with the pure cross flow configuration. 


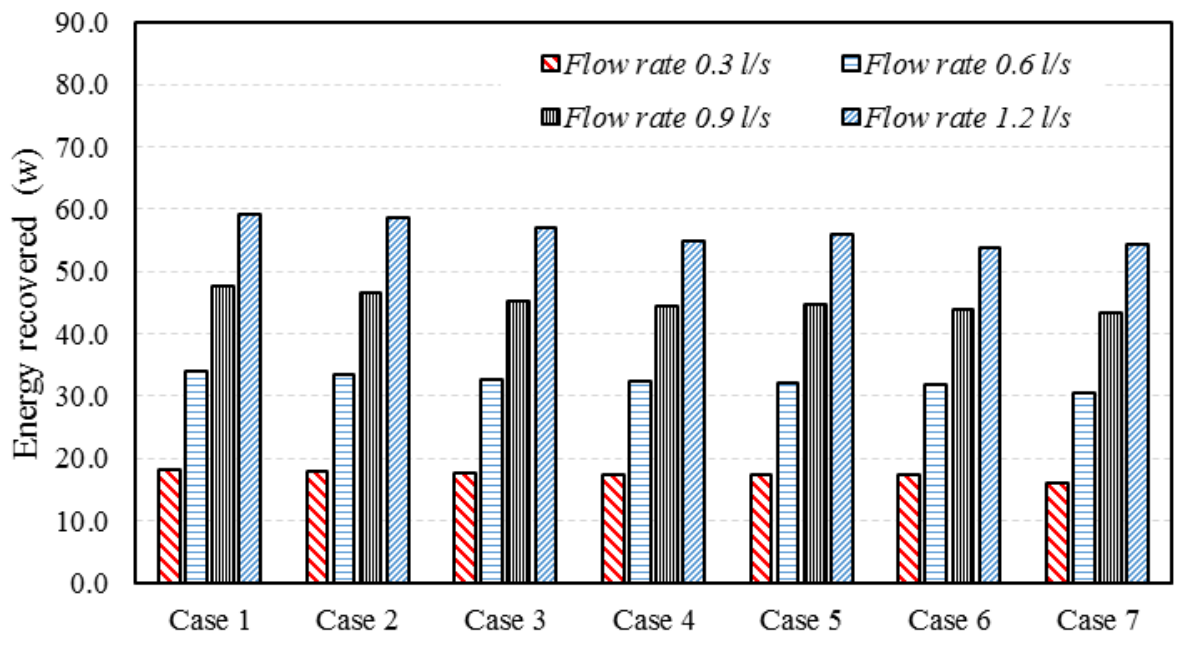

459

Fig. 14 Variations of total energy recovered under different flow rates and various flow configurations.

464 of the energy consumption were similar to those of the recovered energy as the pressure drop 465 increased with the increase of the flow rate. However, the fan power consumption was 466 significantly less than the total energy recovered. In addition, the entrance ratio and the channel 467 shape did not show a significant impact on energy consumption at low flow rate conditions. To 468 sum up, both the recovered energy and consumed energy were a function of the flow rate and 469 flow configuration. A lower flow rate offered a lower pressure drop while a higher flow rate resulted in a high capacity for energy recovery. 


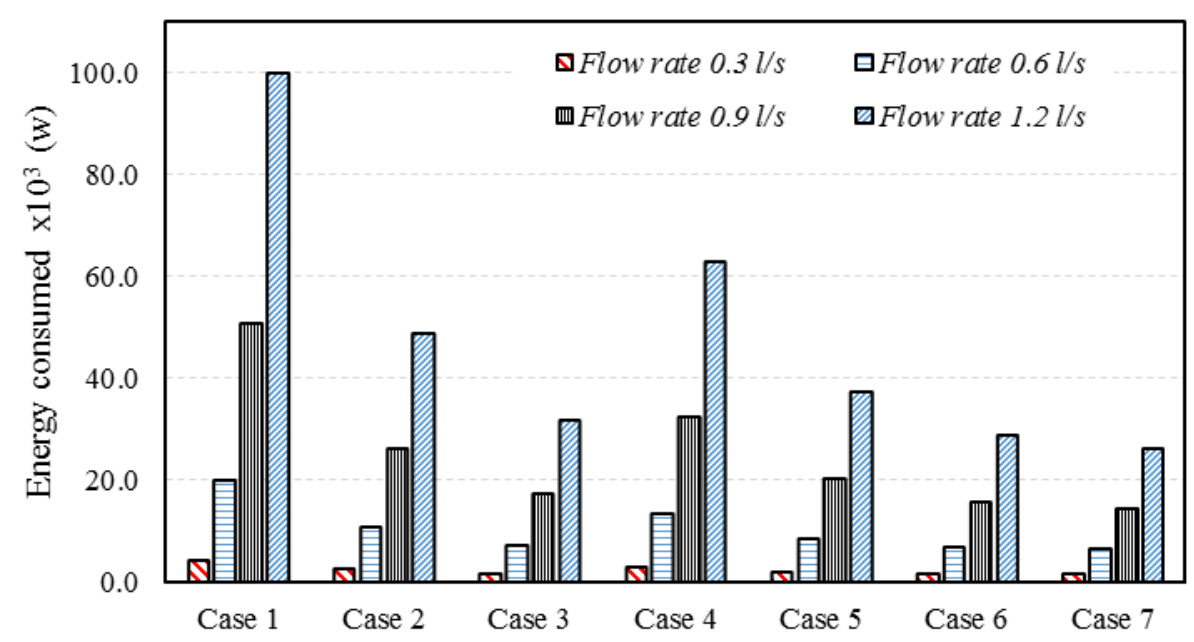

471

Fig. 15 Variations of the fan power consumption under different flow rates and flow configurations.

474 As a summary, the thermal performance of the investigated hybrid flow configurations outperformed the pure cross flow configuration. The Z-shape hybrid flow of the supply air stream and И-shape hybrid flow of the exhaust side at the entrance ratio 0.25 offered the maximum values of the thermal performance and the recovered energy.

\section{Conclusion}

This paper presented the performance evaluation of a mixed-flow enthalpy exchanger through experimental investigation. The measurements of the properties for five porous membranes were first conducted under various test conditions. The values of the moisture diffusivity and the elastic modulus with the uncertainties for the five membranes were presented and evaluated. The results of the measurements showed that the test conditions slightly affected the moisture diffusivity of all the tested membranes. The PVDF45 membrane offered the highest value of the mean moisture diffusivity (i.e. $1.91 \times 10^{-6} \pm 2.42 \times 10^{-8} \mathrm{~m}^{2} / \mathrm{s}$ ). The PVDF22 membrane yielded the highest contact angle of $76.2^{\circ}$ while Nylon45 membrane exhibited the lowest contact angle of 40.5. Three membranes (i.e. PVDF22, Nylon10 and 
PVDF45) showed the similar elastic modulus of around $500 \mathrm{MPa}$ with small differences amongst them. Based on those results, the PVDF45 membrane was employed and used to fabricate a multi-flow configuration membrane enthalpy exchanger core. The developed core allowed to investigate the performance of the enthalpy exchanger under various flow configurations and entrance ratios.

A total of seven different flow configurations were studied including one pure cross flow and six mixed-flow configurations. The results indicated that the thermal performance was improved as the flow rate and entrance ratio decreased. The Z-shape hybrid flow (Case 1) of the supply air stream and И-shape hybrid flow of the exhaust side at the entrance ratio 0.25 yielded the maximum thermal performance as the total effectiveness increased by $14.6 \%$ when the flow rate was $0.31 / \mathrm{s}$, as compared to that of the pure cross flow. The hydrodynamic performance investigation showed that the pressure drop was inversely proportional to the entrance ratio while the flow rate influenced the pressure drop positively. The energy analysis showed that the total energy recovered increased as the flow rate increased. The fan power consumption followed similar behaviours as that of the recovered energy however the energy consumption was much lower than the recovered energy for the same flow configuration and flow rate. A high flow rate was generally preferable for high energy saving applications. The results obtained from this study can be used to develop effective enthalpy exchangers for energy recovery ventilation systems.

\section{Acknowledgements}

The authors would like to thank Mr. Mohammed Almossawi for his work to assist in conducting the tensile tests of the membranes. Ahmed Albdoor would also like to thank the Higher Committee for Education Development (HCED) of Iraq for PhD sponsorship supports.

\section{References}


[1] V. Vakiloroaya, B. Samali, A. Fakhar, K. Pishghadam. A review of different strategies for HVAC energy saving. Energy Conversion and Management. 77 (2014) 738-54.

[2] Z. Duan, C. Zhan, X. Zhang, M. Mustafa, X. Zhao, B. Alimohammadisagvand, et al. Indirect evaporative cooling: Past, present and future potentials. Renewable and Sustainable Energy Reviews. 16 (2012) 6823-50.

[3] W. Lin, Z. Ma, M.I. Sohel, P. Cooper. Development and evaluation of a ceiling ventilation system enhanced by solar photovoltaic thermal collectors and phase change materials. Energy Conversion and Management. 88 (2014) 218-30.

[4] K.J. Chua, S.K. Chou, W.M. Yang, J. Yan. Achieving better energy-efficient air conditioning - A review of technologies and strategies. Applied Energy. 104 (2013) 87-104. [5] Z. Ma, H. Ren, W. Lin. A review of heating, ventilation and air conditioning technologies and innovations used in solar-powered net zero energy Solar Decathlon houses. Journal of Cleaner Production. 240 (2019) 118158.

[6] Z. Wang, F. Wang, Z. Ma, M. Song. Numerical study on the operating performances of a novel frost-free air-source heat pump unit using three different types of refrigerant. Applied Thermal Engineering. 112 (2017) 248-58.

[7] P. Liu, M. Rafati Nasr, G. Ge, M. Justo Alonso, H.M. Mathisen, F. Fathieh, et al. A theoretical model to predict frosting limits in cross-flow air-to-air flat plate heat/energy exchangers. Energy and Buildings. 110 (2016) 404-14.

[8] A.K. Albdoor, Z. Ma, P. Cooper. Moisture diffusion measurement and evaluation for porous membranes used in enthalpy exchangers. Energy Procedia. 160 (2019) 499-506. [9] D. O’Connor, J.K.S. Calautit, B.R. Hughes. A review of heat recovery technology for passive ventilation applications. Renewable and Sustainable Energy Reviews. 54 (2016) 1481-93. 

recovery exchangers for use in ZEBs in cold climate countries. Building and Environment. 84 (2015) 228-37.

[11] A. Engarnevis, R. Huizing, S. Green, S. Rogak. Heat and mass transfer modeling in enthalpy exchangers using asymmetric composite membranes. Journal of Membrane Science. 556 (2018) 248-62.

[12] L.Z. Zhang. Progress on heat and moisture recovery with membranes: From 173-95.

[13] G. Ge, G.I. Mahmood, D.G. Moghaddam, C.J. Simonson, R.W. Besant, S. Hanson, et al.

Material properties and measurements for semi-permeable membranes used in energy exchangers. Journal of Membrane Science. 453 (2014) 328-36.

[14] J.L. Niu, L.Z. Zhang. Membrane-based Enthalpy Exchanger: material considerations and clarification of moisture resistance. Journal of Membrane Science. 189 (2001) 179-91. [15] J. Min, M. Su. Performance analysis of a membrane-based enthalpy exchanger: Effects of the membrane properties on the exchanger performance. Journal of Membrane Science. 348 (2010) 376-82.

[16] M.D. Larson, R.W. Besant, C.J. Simonson. The Effect of Membrane Deflections on Flow Rate in Crossflow Air-to-Air Exchangers. HVAC\&R Research. 14 (2008) 275-88. [17] M.R.H. Abdel-Salam, R.W. Besant, C.J. Simonson. Performance testing of 2-fluid and climates. International Journal of Heat and Mass Transfer. 106 (2017) 558-69. 
[19] M. Yang, S.M. Huang, X. Yang. Experimental investigations of a quasi-counter flow parallel-plate membrane contactor used for air humidification. Energy and Buildings. 80 (2014) 640-4.

[20] S.M. Huang, M. Yang, X. Yang. Performance analysis of a quasi-counter flow parallelplate membrane contactor used for liquid desiccant air dehumidification. Applied Thermal Engineering. 63 (2014) 323-32.

[21] A. Vali, G. Ge, R.W. Besant, C.J. Simonson. Numerical modeling of fluid flow and coupled heat and mass transfer in a counter-cross-flow parallel-plate liquid-to-air membrane energy exchanger. International Journal of Heat and Mass Transfer. 89 (2015) 1258-76. [22] M.S. Nasif, R.f. Al-Waked, M. Behnia, G. Morrison. Modeling of Air to Air Enthalpy Heat Exchanger. Heat Transfer Engineering. 33 (2012) 1010-23.

[23] M.S. Nasif, R. Al-Waked, M. Behnia, G. Morrison. Air to air fixed plate enthalpy heat exchanger, performance variation and energy analysis. Journal of Mechanical Science and Technology. 27 (2013) 3541-51.

[24] M. Nasif, R. Al-Waked, G. Morrison, M. Behnia. Membrane heat exchanger in HVAC energy recovery systems, systems energy analysis. Energy and Buildings. 42 (2010) 1833-40. [25] L.Z. Zhang. Heat and mass transfer in a quasi-counter flow membrane-based total heat exchanger. International Journal of Heat and Mass Transfer. 53 (2010) 5478-86.

[26] R. Al-Waked, M.S. Nasif, D.B. Mostafa. Enhancing the performance of energy recovery ventilators. Energy Conversion and Management. 171 (2018) 196-210.

[27] BS EN 308:1997, Heat exchangers. Test procedures for establishing theperformance of air to air and flue gases heat recovery devices. 1997.

[28] B. Yang, W. Yuan, F. Gao, B. Guo. A review of membrane-based air dehumidification. Indoor and Built Environment. 24 (2013) 11-26. 

water vapor and inert gas mixtures through highly selective and highly permeable polymer membranes. Journal of Membrane Science. 251 (2005) 29-41. [30] V.I. Bondar, B.D. Freeman, I. Pinnau. Gas transport properties of poly(ether-b-amide) segmented block copolymers. Journal of Polymer Science Part B: Polymer Physics. 38 (2000) 2051-62.

[31] Y. Li, T.S. Chung. Highly selective sulfonated polyethersulfone (SPES)-based membranes with transition metal counterions for hydrogen recovery and natural gas separation. Journal of Membrane Science. 308 (2008) 128-35.

[32] L. Martínez, F.J. Florido-Díaz, A. Hernández, P. Prádanos. Estimation of vapor transfer coefficient of hydrophobic porous membranes for applications in membrane distillation. Separation and Purification Technology. 33 (2003) 45-55. using ionic liquid and PVDF hollow fiber as a support for CO2/N2 separation. Journal of Membrane Science. 372 (2011) 346-54.

[34] ASTM E96/E96 M-05. Standard test methods for water vapor transsmission of materials, ASTM International, West Conshohocken. 2005.

604

[35] P. Liu, M. Justo Alonso, H.M. Mathisen, C. Simonson. Performance of a quasi-counterflow air-to-air membrane energy exchanger in cold climates. Energy and Buildings. 119 (2016) 129-42.

[36] J. Min, M. Su. Performance analysis of a membrane-based energy recovery ventilator: Effects of outdoor air state. Applied Thermal Engineering. 31 (2011) 4036-43. (2013) 770-80. 
612 [38] X.R. Zhang, L.Z. Zhang, H.M. Liu, L.X. Pei. One-step fabrication and analysis of an 613 asymmetric cellulose acetate membrane for heat and moisture recovery. Journal of Membrane 614 Science. $366(2011)$ 158-65.

615 [39] L.Z. Zhang. Heat and mass transfer in a cross-flow membrane-based enthalpy exchanger 616 under naturally formed boundary conditions. International Journal of Heat and Mass

617 Transfer. 50 (2007) 151-62.

618 [40] W. Yang, L. Sun, Y. Chen. Experimental investigations of the performance of a solar619 ground source heat pump system operated in heating modes. Energy and Buildings. 89 (2015) $620 \quad 97-111$.

621 [41] J. Min, T. Hu, X. Liu. Evaluation of moisture diffusivities in various membranes.

622 Journal of Membrane Science. 357 (2010) 185-91.

623 [42] J. Min, J. Duan. Comparison of various methods for evaluating the membrane-type total 624 heat exchanger performance. International Journal of Heat and Mass Transfer. 100 (2016) $625 \quad 758-66$. 